UCRL-ID-126085

\title{
A High Shear Stress Segment along the San Andreas Fault: Inferences Based on Near-Field Stress Direction and Stress Magnitude Observations in the Carrizo Plain Area
}

\author{
David A. Castillo
}

Leland W. Younker

January 30, 1997

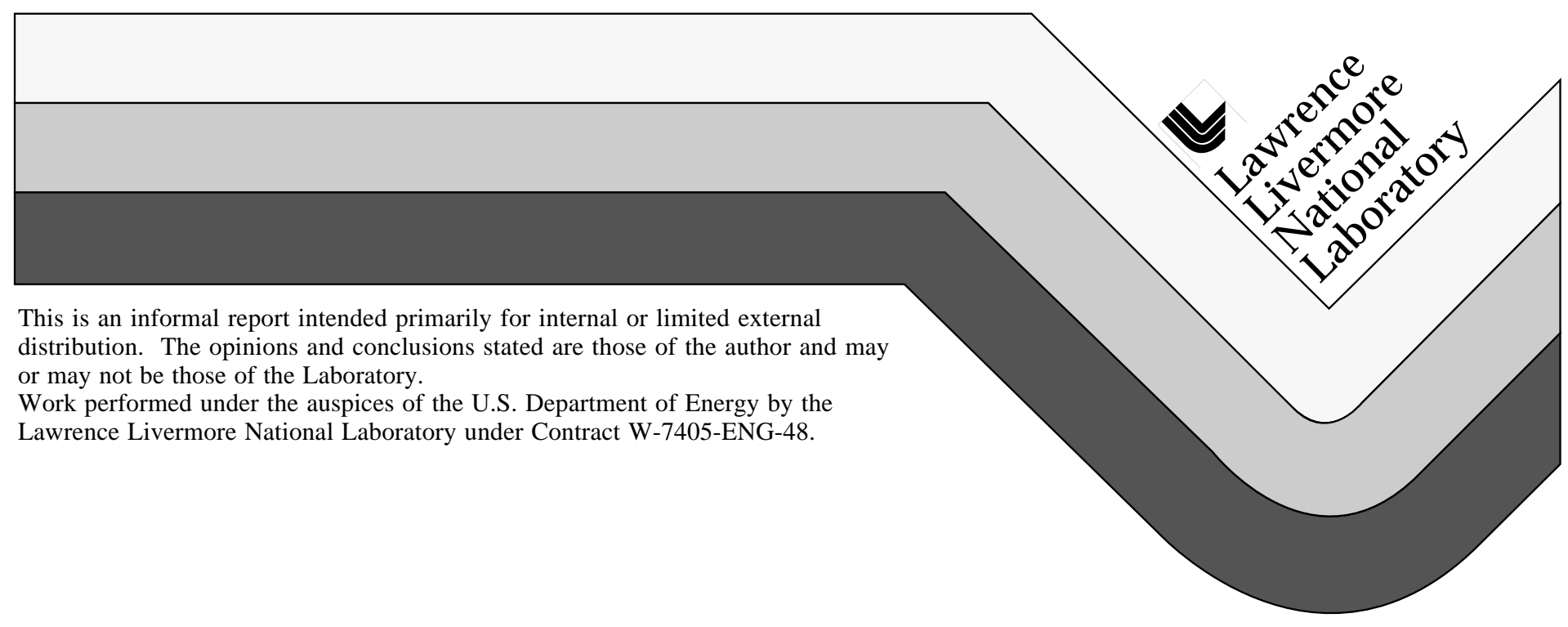




\section{DISCLAIMER}

This document was prepared as an account of work sponsored by an agency of the United States Government. Neither the United States Government nor the University of California nor any of their employees, makes any warranty, express or implied, or assumes any legal liability or responsibility for the accuracy, completeness, or usefulness of any information, apparatus, product, or process disclosed, or represents that its use would not infringe privately owned rights. Reference herein to any specific commercial product, process, or service by trade name, trademark, manufacturer, or otherwise, does not necessarily constitute or imply its endorsement, recommendation, or favoring by the United States Government or the University of California. The views and opinions of authors expressed herein do not necessarily state or reflect those of the United States Government or the University of California, and shall not be used for advertising or product endorsement purposes.

This report has been reproduced directly from the best available copy.

Available to DOE and DOE contractors from the Office of Scientific and Technical Information

P.O. Box 62, Oak Ridge, TN 37831

Prices available from (615) 576-8401, FTS 626-8401

Available to the public from the

National Technical Information Service

U.S. Department of Commerce 5285 Port Royal Rd.,

Springfield, VA 22161 


\section{A High Shear Stress Segment along the San Andreas Fault: Inferences Based on Near-Field Stress Direction and Stress Magnitude Observations in the Carrizo Plain Area}

David A. Castillo* and Leland W. Younker

Lawrence Livermore National Labortory

Livermore, California 94551

* Now at:

Department of Geology and Geophysics, University of Adelaide, Adelaide, South Australia, AUSTRALIA 5073

Email: castillo@timor.geology.adelaide.edu.au

Phone: (61-08-8303-3870)

Fax: (61-08-8303-4347) 


\section{Abstract}

Nearly 200 new in-situ determinations of stress directions and stress magnitudes near the Carrizo plain segment of the San Andreas fault (SAF) indicate a marked change in stress state occurring within $20 \mathrm{~km}$ of this principal transform plate boundary. The predominant maximum principal stress direction $\left(\mathrm{S}_{\mathrm{Hmax}}\right)$, inferred from stress-induced breakouts in about 25 industry wells within 3-20 km of the San Andreas fault indicate a $S_{\text {Hmax }}$ orientation that varies between $25-45^{\circ}$ from the fault trend. Additional in-situ observations in wells located beyond $20 \mathrm{~km}$ of the fault indicate a stress state consistent with previous observations of $\mathrm{S}_{\mathrm{Hmax}}$ oriented at high angles $\left(65-85^{\circ}\right)$ to SAF. These new in-situ stress observations in wells located on either side of the fault and at depths ranging from $0.5-7.4 \mathrm{~km}$, show a marked transition occurring at about 20 $\mathrm{km}$ from the SAF, where the $S_{\mathrm{Hmax}}$ directions changes from "fault-normal" to "fault-oblique" compression. Estimates of the minimum principal stress $\left(\mathrm{S}_{\mathrm{hmin}}\right)$ magnitude depth-profile, inferred from several hydraulic fracturing treatments in production fields situated within 16-25 $\mathrm{km}$ east of the SAF, indicate a strike-slip stress regime with $\mathrm{S}_{\mathrm{hmin}} / \mathrm{S}_{\mathrm{v}} \sim 0.7$. Estimates of $\mathrm{S}_{\mathrm{Hmax}}$ magnitudes based on frictional faulting theory and the observed style of faulting (strike-slip and reverse faulting), suggest that the level of shear stress on SAF-parallel planes increases towards the fault.

A natural consequence of this stress transition at $20 \mathrm{~km}$ distance from the fault is that if the observed near-field "fault-oblique" stress directions are representative of the fault stress state, the Mohr-Coulomb shear stresses resolved on San Andreas sub-parallel planes is substantially greater than previously inferred based on fault-normal compression. Although the directional stress data and near-hydrostatic pore pressures, which exist within $15 \mathrm{~km}$ of the fault, supports a high shear stress environment near the fault, appealing to elevated pore pressures in the fault zone (Byerlee-Rice Model) merely enhances the likelihood of shear failure.

These near-field stress observations within $20 \mathrm{~km}$ of the San Andreas fault raises important questions regarding what previous stress observations have actually been measuring. The "faultnormal" stress direction measured out to $70 \mathrm{~km}$ from the fault can be interpreted as representing a comparable depth average shear strength of the principal plate boundary. Stress measurements closer to the fault reflects a shallower depth-average representation of the fault zone shear strength. If this is true, only stress observations at fault distances comparable to the seismogenic depth, will be representative of the fault zone shear strength. This is consistent with results from dislocation modeling where there is a pronounced shear stress accumulation out to $20 \mathrm{~km}$ of the fault as a result of aseismic slip within the lower crust loading the upper locked section. Beyond about $20 \mathrm{~km}$, the shear stress resolved on San Andreas fault-parallel planes becomes negligible. 


\section{Introduction}

Over the past 30 years, much has been learned about the kinematics of transform fault motion, in particular, from work conducted along the San Andreas fault in California. Although recent advances in seismological, geodetic, and wellbore measurements have greatly improved our understanding of this major plate boundary, there remains several unresolved issues.

Probably the most paramount of these issues is what has been called within the scientific community as the San Andreas stress/heat-flow paradox. Laboratory simulations of frictional faulting would suggest a "strong" San Andreas fault with shear stresses, averaged over seismogenic depths (upper $20 \mathrm{~km}$ ) ranging from 50-100 MPa (e.g., Byerlee, 1978; Sibson, 1973, 1983; Brace and Kohlstedt, 1980). The shear stresses implied by a "weak" San Andreas would be on the order of the earthquake stress drops, or less than $20 \mathrm{MPa}$ (e.g., Lachenbruch and Sass, 1980). The lack of a appreciable long-term frictional heat-flow anomaly along the SAF would be consistent with a "weak" fault (Brune et al, 1969; Henyey and Wasserberg, 1971; Lachenbruch and Sass, 1973, 1980).

Within the past decade, in-situ data collected adjacent to the San Andreas supports the concept of a "weak" fault, based on the analysis of earthquake focal mechanisms and stressinduced wellbore breakouts indicating that the maximum horizontal principal stress $\left(\mathrm{S}_{\mathrm{Hmax}}\right)$ is at high angles (about $65-85^{\circ}$ ) to the San Andreas (Zoback et al., 1987; Mount and Suppe, 1987; Jones, 1988; Oppenheimer et al., 1988). A majority of these observations come from either well data in the Central Valley but beyond $20 \mathrm{~km}$ or so from the San Andreas, although, a few of the earthquake focal mechanism solutions are from the fault zone itself (Zoback and Beroza, 1993). That fault-parallel fold axes ocurr along the western margin of the Central Valley, implies that this "fault normal" $\mathrm{S}_{\mathrm{Hmax}}$ orientation exist within $20 \mathrm{~km}$ of the fault despite the lack of reliable well data (Zoback et al., 1987; Mount and Suppe, 1987). Nonetheless, the lack of a frictional heat-flow anomaly, a regional "fault-normal" $\mathrm{S}_{\mathrm{Hmax}}$ orientation, and fault-parallel fold axes points to the hypothesis that the San Andreas fault is a "weak" plate boundary.

The heat-flow and directional stress constraints along the SAF can be satisfied by a marked decrease in the coefficient of friction of the fault gouge materials from $\mu=0.6-0.8$ (Byerlee, 1978) to $\mu<0.2$. Moore et al., (1996) has recently demonstrated that the serpentinite mineral chrysotile, originally thought to have explained the relative weaknesses inherit in fault gouge materials, approaches coefficients of friction typical of Byerlee's results at relatively high confining stresses. Therefore, a marked reduction in the coefficient of friction reduction is insufficient to explain the low shear stresses inferred from the in-situ data (heat-flow and stress directions).

Elevating the in-situ pore pressure would reduce the effective normal stress, however, high fluid pressures cannot exceed the least principal stress once the angle between $\mathrm{S}_{\mathrm{Hmax}}$ and the fault exceds $\sim 60^{\circ}$ (Scholz, 1989; Lachenbruch and McGarr, 1990). Large-scale yielding could 
lead to an increase in the magnitudes of the principal stresses within the fault zone relative to values immediately outside the fault (e.g., Byerlee, 1990; Rice, 1992). This increase in stress magnitudes could support an elevation in pore pressure, and thereby, rotate the stress field within the fault zone.

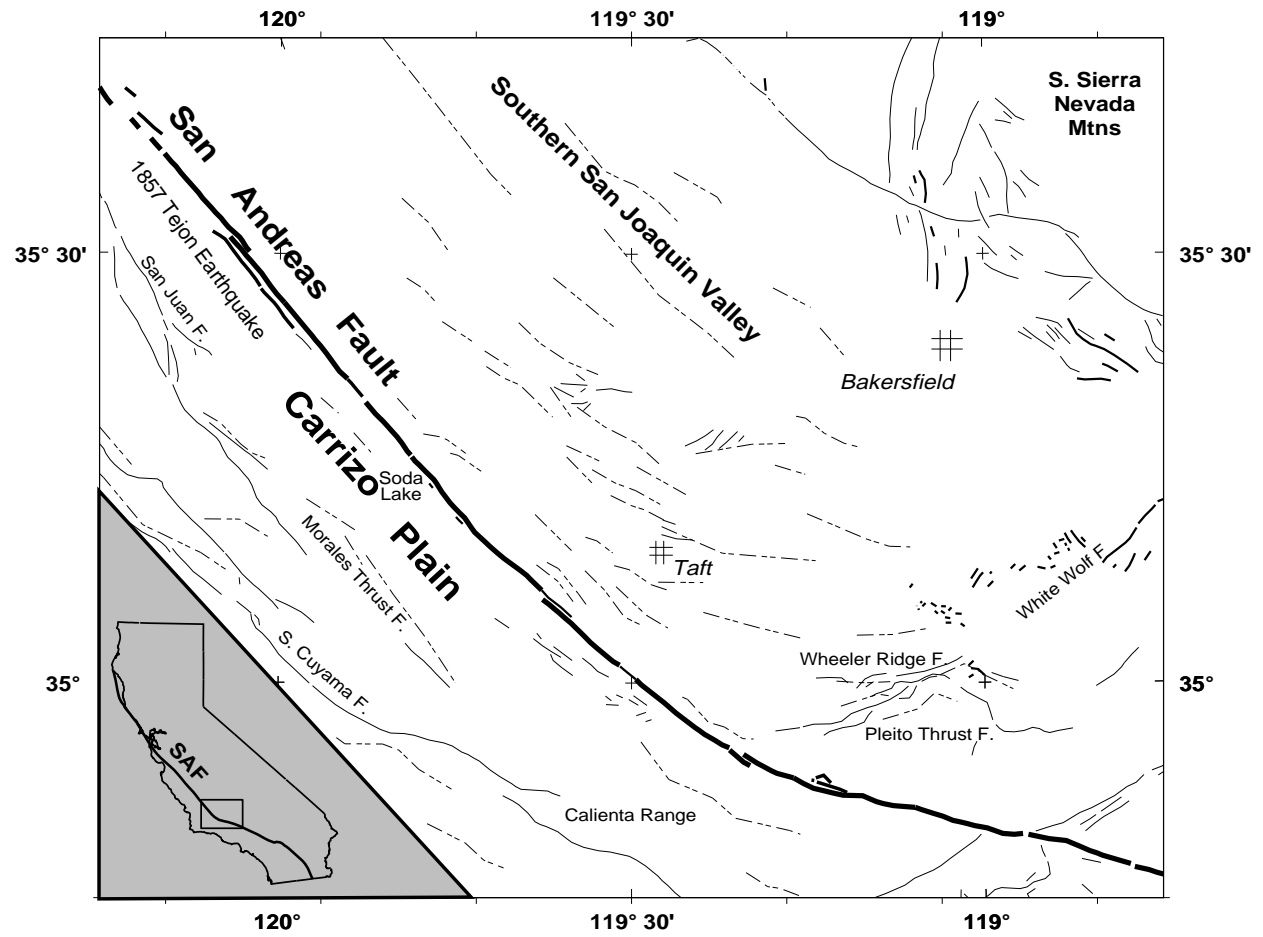

Figure 1. Location map of the San Andreas fault along the Carrizo Plain segment in central California. Bold fault lines correspond to faults that have ruptured in historic time, such as the $1857 \sim \mathrm{M} 8$ Tejon earthquake along the San Andreas fault and the 1952 M7.8 Kern County earthquake along the White Wolf fault. Other faults delineate rupture in Quaternary time. Dashed line correspond to fold axes of Pliocene age or younger.

Several dynamic mechanisms have been proposed that might explain the low strength of the SAF appealing to processes associated directly with the propagation of seismic rupture. These processes range from transient high fluid pore pressure (Lachenbruch, 1980), dilational waveinduced reductions in normal stress (Brune, 1993), and fluidization of fault zone material due to channeling of acoustic waves (Melosh, 1979, 1996).

Despite the recent surge in proposed explanations for a "weak" SAF, the physical mechanism(s) governing the strength of the SAF are far from being clearly understood. For instance, we have no direct in-situ evidence at seismogenic depths that can be used to evaluate fault zone dynamics in terms of structure, stress, fluids, and chemical processes. To begin addressing these discrepancies, a joint effort between LLNL, U.S. Geological Survey, and Stanford University has been gaining momentum design to drill a $10 \mathrm{~km}$ deep hole into the San 
Andreas fault, penetrating the fault at several depths. This report reflects an intiative undertaken at LLNL to characterize the stress state along key segments of the fault for drill site selection. This is particularly important since it will be of paramount importance that data collected during deep drilling into the SAF be interpreted in context of the surrounding crust.

In this study, we have collected an abundance of in-situ stress directions and stress magnitudes from the petroleum industry, especially within $20 \mathrm{~km}$ of the fault. This has given us an unprecedented opportunity to examine the near-field stress state to within $3 \mathrm{~km}$ of the SAF. A equally important intiative, pioneered by LLNL has been to create new tools and technologies necessary to drill and collect critical data in the harsh physical environments expected at these drilling depths.

\section{Background}

The Carrizo Plain segment of the San Andreas fault proper is the simplest and easily recognized segment of this major plate boundary. In the Carrizo plain region, the SAF divides a $8 \mathrm{~km}+$ sequence of marine sediments of the southern San Joaquin Valley to the northeast, from a sequence of non-marine sediments and crystalline rocks of the Salinian Terrane to the southwest (Graham and Olsen, 1988). The well-delineated and narrow ( few kilometers) trace of the SAF within the northern limits of the Carrizo Plain, develops into a series of pressure ridges further south as the SAF progressively turn eastward (Figure 1). Offset stream drainage and other geomorphic features provides quantitative evidence of strike-slip motion along this major plate boundary (Lawson et al., 1908; Wallace, 1968; Sieh and Jahns, 1984; Grant and Sieh, 1994; Grant and Donnellan, 1994). The SAF last ruptured in this regions in the Great $1857 \mathrm{M}=7.8$ Fotrt Tejon earthquake (Ellsworth, 1990) along a total length of about $300 \mathrm{~km}$ with as much as 9$11 \mathrm{~m}$ of slip along the Carrizo plain segment (Grant and Donnellan, 1994). The lack of current seismicity and paleoseismic studies suggest that the Carrizo plain segment ruptures only during great earthquakes (Sims, 1993). The accumulated transform slip over the past 15-20 Ma, when motion initiated in the Carrizo plain, has been about $315 \mathrm{~km}$ (Graham et al, 1989; Sims, 1993). The average slip rate up to about $5 \mathrm{Ma}$ is about $10 \mathrm{~mm} / \mathrm{yr}$, increasing to a present-day slip rate of about $33 \mathrm{~mm} / \mathrm{yr}$ based on paleoseismic and geodetic evidence (Sieh and Jahns, 1984; EberhartPhillips et al., 1990; Lisowski et al., 1991; Grant and Sieh, 1993; Grant and Donnellan, 1994).

The stress maps in Central California prior to this study presented striking evidence that the San Andreas may be a "weak" plate boundary (Zoback et al., 1987; Mount and Suppe, 1987). Observations of wellbore breakouts and earthquake focal mechanisms ranging in distance from a few kilometers to $\sim 70 \mathrm{~km}$ from the fault, and along a distance that nearly stretches its entire length, have long been regarded as representative of the stress state resolved on the San Andreas. Although there were few in-situ measurements within $20 \mathrm{~km}$ of the fault, particularly in Central 
California, evidence supporting the notion that this fault-normal stress state extended up to the fault were the SAF-parallel fold axes (Figure stress).

\section{Near-Field In-Situ Stress Data}

Data from over 300 wells have been analyzed for stress-induced wellbore breakouts and pore pressure estimates adjacent to the Carrizo plain segment of the San Andreas fault (SAF). A majority of the wells are located northeast of the SAF in the San Joaquin basin, although several critical wells are situated in the Carrizo plain area southwest of the fault. Depths over which reliable data were obtained ranges from about $0.5-7.4 \mathrm{~km}$ deep, with the most reliable stress indicators generally restricted to $1 \mathrm{~km}$ or deeper. Estimates of the stress orientation ranged from 3- $65 \mathrm{~km}$ from the San Andreas fault in wells located primarily in active hydrocarbon production fields. Without exception, wells located within $15 \mathrm{~km}$ of the San Andreas were drilled as hydrocarbon exploration 'wildcat' wells.

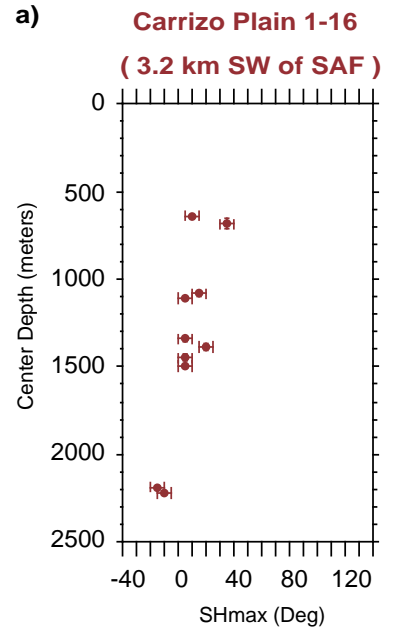

b)

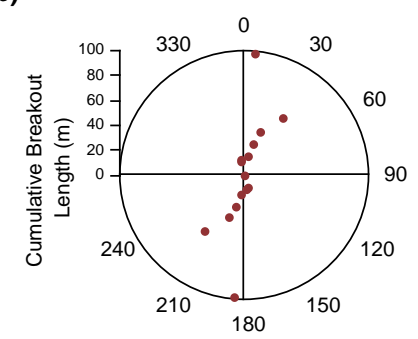

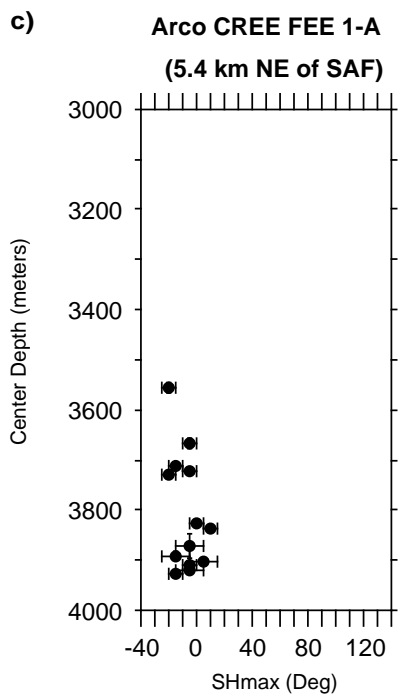

d)

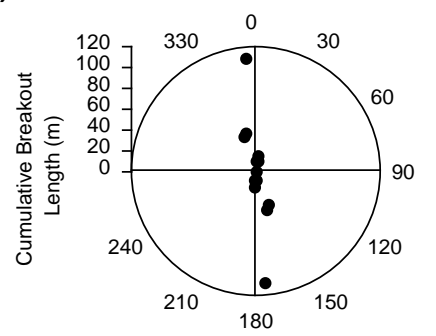

Figure 2. SHmax stress directions for selected wells in the Carrizo Plain area. Top plot for each well shows SHmax directions versus depth inferred from wellbore breakouts with horizontal error-bars corresponding to directional uncertainties. Vertical bars for each point illustrates the Vertcal extent along which the breakout was observed. The bottom plot for each well represents the length-weighted S Hmax directions for data in that specfic well. a) and b) Carrizo Plain 1-16; c) and d) Arco Cree Fee 1A; e) and f) Tenneco TWI Fee 1-33; g) and h) Grayson Owen 1-35; i) and j) UO-NPR 385-12Z; k) and l) UO-NPR 934-29R. 
e)

Tenneco TWI Fee 1-33

( $7 \mathrm{~km} \mathrm{SW}$ of SAF )

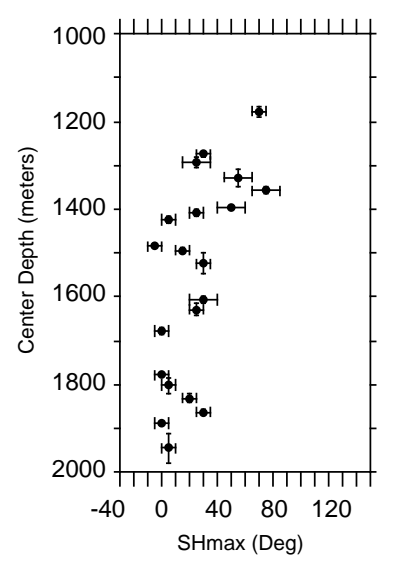

f)

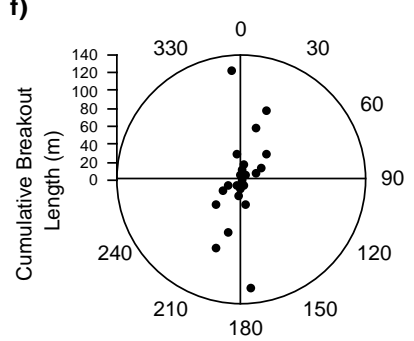

g) Grayson Owen 1-35

(13.5 km SW of SAF)

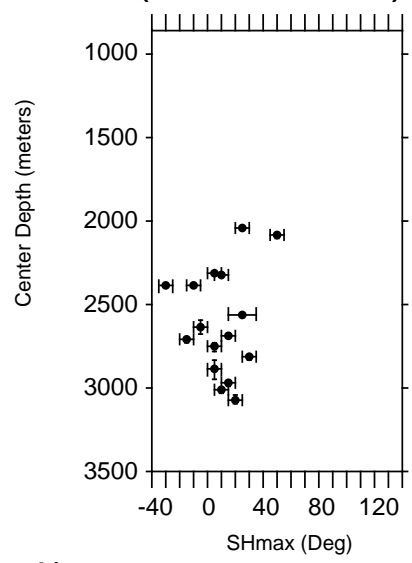

h)

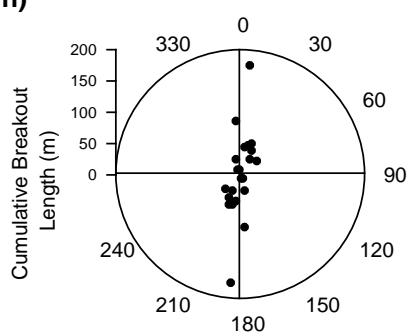

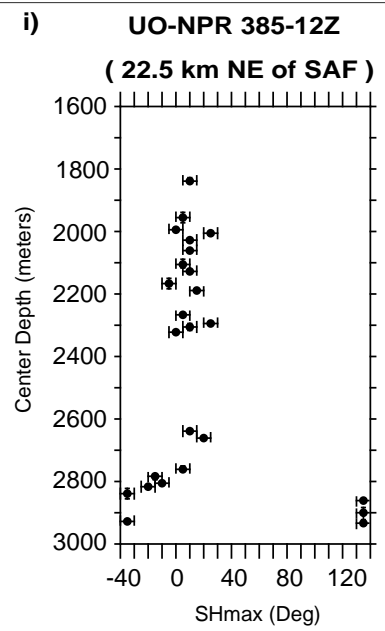

j)

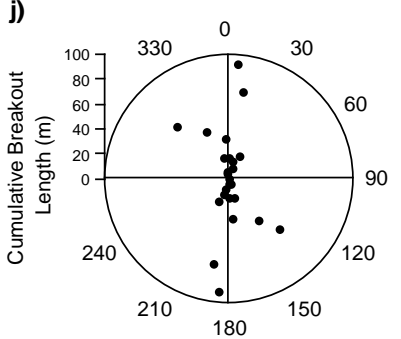

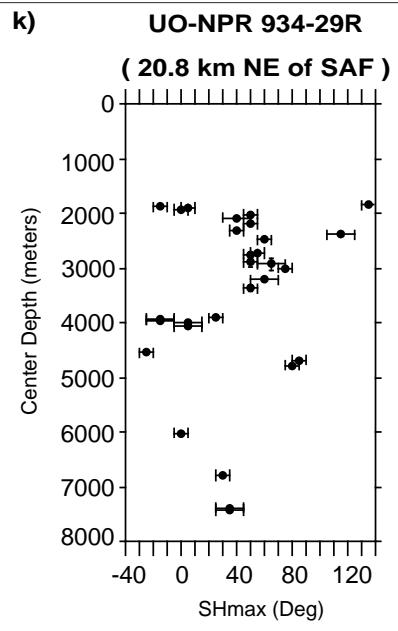

l)

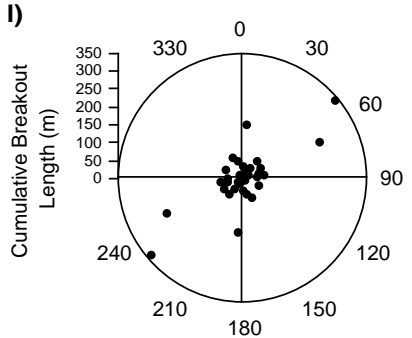

Figure 2. Continued 
A catalog of $\mathrm{S}_{\mathrm{Hmax}}$ directions inferred from stress-induced wellbore breakouts is the primary contribution in this manuscript. Two hundred of the 300 or so wells used in this study indicated reliable wellbore breakout directions, which in theory, are aligned perpendicular to the maximum principal horizontal stress $\left(\mathrm{S}_{\mathrm{Hmax}}\right)$. The cummulative length of breakout intervals observed for the entire study was in excess of 15,000 meters, with representative examples of average directions for selected wells shown in Figures 2a-21. Only stress data for a particular wells where the total variability was less than $25^{\circ}$ are shown in these figures. For comparison, data of quality A and B from the World Stress Data Base (Zoback and Zoback, 1991) are also shown.

a)

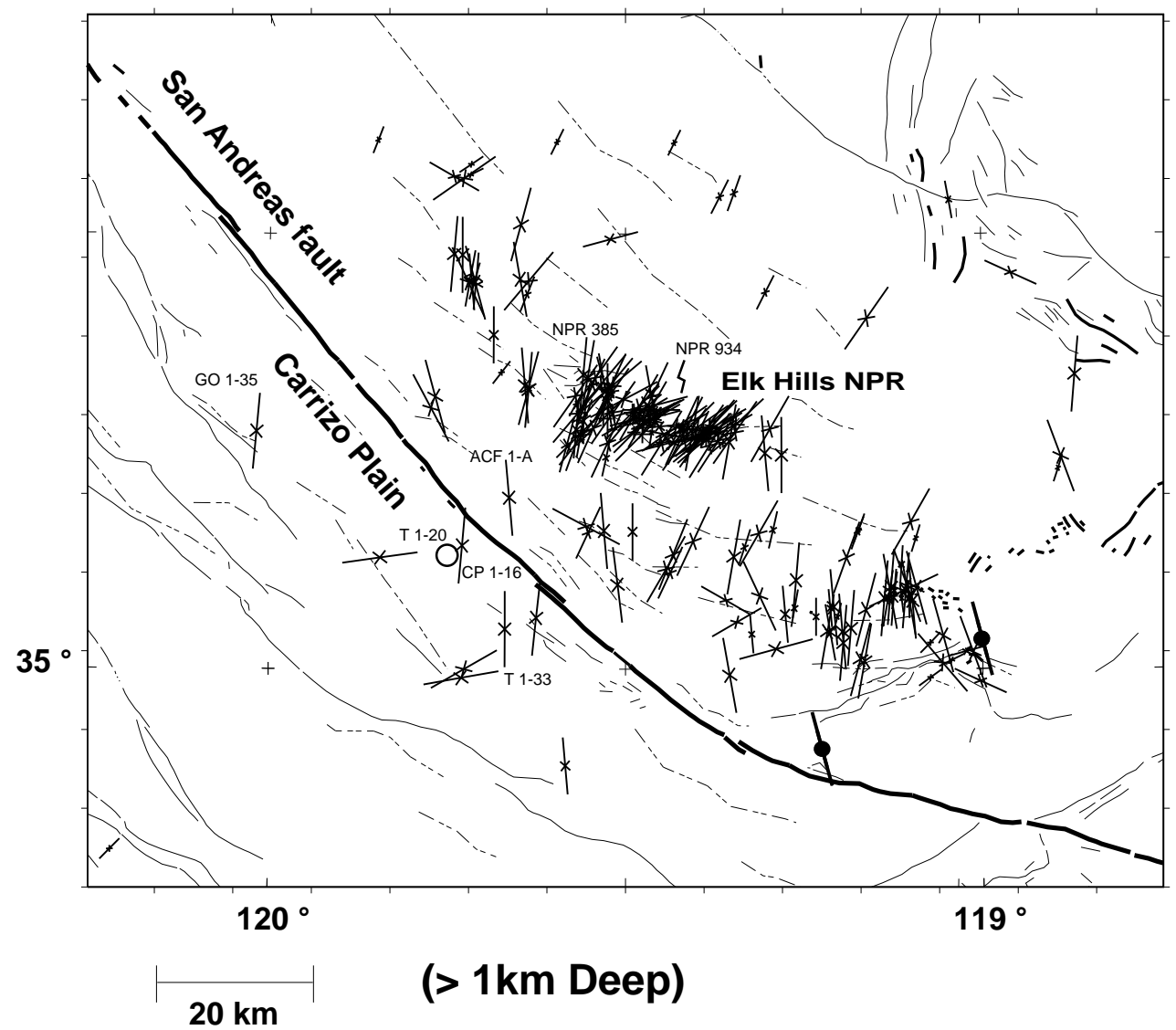

Figure 3 Maps showing the maximum principal stress orientations $\left(\mathrm{S}_{\mathrm{Hmax}}\right)$ along the San Andreas fault and surrounding regions at different observation depths. Inward facing arrows are stress indicators inferred from wellbore breakouts while the circled symbols are stress indicators inferred from focal mechanism inversions. a) Stress directions using data $1 \mathrm{~km}$ and deeper. b) Stress directions using data $2 \mathrm{~km}$ and deeper. c) Stress directions using data $3 \mathrm{~km}$ and deeper. Stress observations situated $20 \mathrm{~km}$ or more from the San Andreas fault suggest that the fault has little shear stress resolved on it, while data within $20 \mathrm{~km}$, showing stress directions that are $30-45^{\circ}$ from the fault and in some cases as close as $3 \mathrm{~km}$, suggest relatively high levels of shear stress resolved on the fault. CP 1-16, Carrizo Plain 1-16; T 1-20, Tenneco 1-20; T 1-33, Tenneco TWI Fee 1-33; GO 1-35, Grayson Owen 1-35; ACF 1-A, Arco CREE Fee 1-A; NPR 385, UO-NPR 385-12Z; NPR 934, UO-NPR 934-29R 
b)

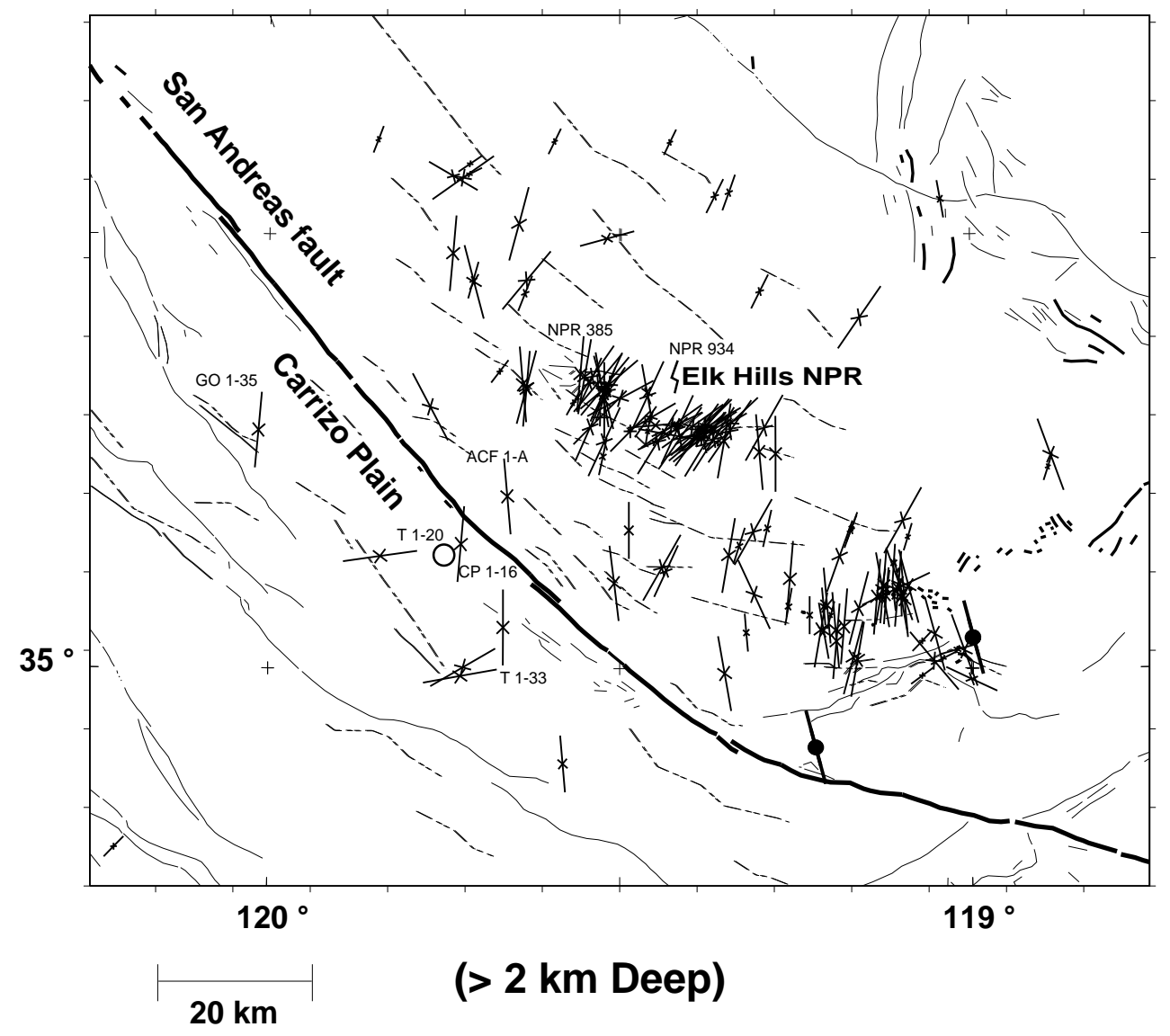

Figure 3 Continued 
c)

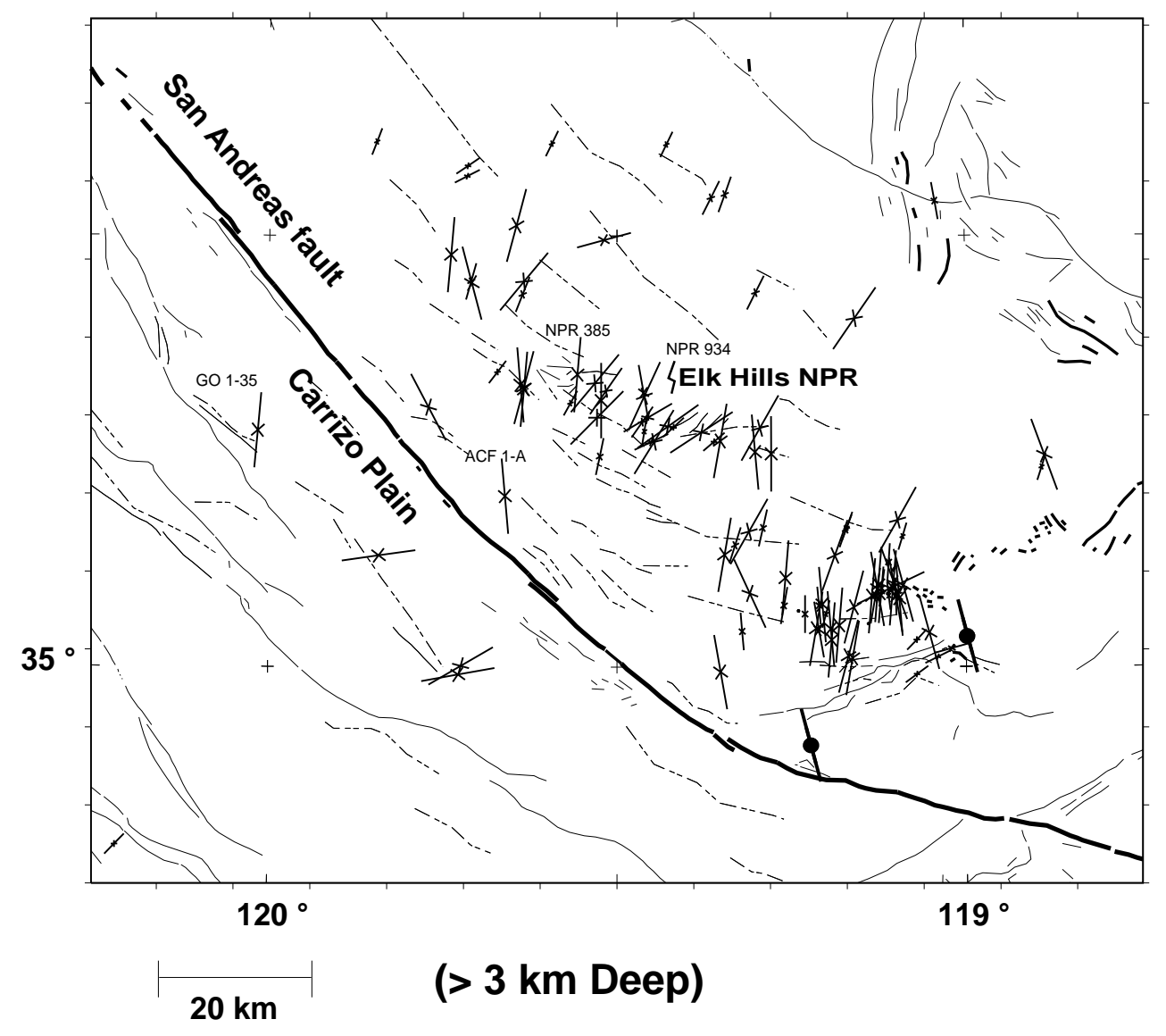

Figure 3 Continued 
Examples of $\mathrm{S}_{\mathrm{Hmax}}$ stress directions inferred from wellbore breakouts in 5 wells are shown in Figures 2a-21. These wells are located between 5.4 and $22.5 \mathrm{~km}$ from the San Andreas fault with observations ranging from $0.5-7.4 \mathrm{~km}$ deep. The deepest stress observation at $7.4 \mathrm{~km}$ depth was measured in well UO-NPR 934-29R situated about $21 \mathrm{~km}$ northeast of the San Andreas (Figures $2 \mathrm{k}$ and 21) indicating a dominant northeast-southwest $\mathrm{S}_{\mathrm{Hmax}}$ stress direction, consistent with previous observations (Zoback, et al., 1987; Mount and Suppe, 1987). However, wells located closer to the San Andreas fault display a markedly different $\mathrm{S}_{\mathrm{Hmax}}$ direction. The average $S_{H \max }$ direction seen in Carrizo 1-16 and Arco Cree Fee 1-A (Figure 3), located within $5.4 \mathrm{~km}$ of the San Andreas fault, indicates a well-pronounced north-south orientation at a depth of about 2.5 and $4 \mathrm{~km}$, respectively. Examples of shallower stress measurements in Tenneco TWI Fee 1-33 ( 1.9 km deep) and Grayson Owen 1-35 ( $3.1 \mathrm{~km}$ deep), located 7 and $13.5 \mathrm{~km}$

southwest of the San Andreas fault, respectively, also indicate a consistent north-south $\mathrm{S}_{\mathrm{Hmax}}$ direction (Figures 2d-2e).

The small-scale variations in the stress versus depth plots (Figures 2a-2l) are indicators of local perturbations in the stress field where the wellbore has possibly intersected faults and/or fractures. In cases where computed dip-meter logs were available in the intervals of these local stress perturbations, there were pronounced structural discontinuities that may be due to faulting. Examples of these small scale and local stress variations have been observed elsewhere in the San Joaquin basin (Castillo and Zoback, 1994) and in other stress provinces (Barton and Zoback, 1994).

\section{Non-uniform stress field}

The non-uniformity in the stress state adjacent to the Carrizo plain segment of the San Andreas fault is best illustrated in map view and as plots showing stress directions versus distance from the San Andreas (Figures 3, 4, and 5). We've chosen to show the average stress direction for each well in terms of observation depths. For instance, Figure 3a is a map showing stress directions from observations $1 \mathrm{~km}$ or deeper. Figures $3 \mathrm{~b}$ and $3 \mathrm{c}$ correspond to average stress directions from those wells with observations deeper than $2 \mathrm{~km}$ and $3 \mathrm{~km}$, respectively. In many cases where breakouts were observed over depths of several kilometers, the same average stress direction will appear on subsequent maps showing deeper data. Aside from the smallscale stress variations seen in a few of the wells (Figure 3) there were no large scale changes in the stress field in any particular well that would suggest systematic and depth dependent rotations in the stress field. To avoid stress complications related to the 'big bend' segment of the San Andreas fault, our discussions will be restricted to those data on either side of the linear Carrizo plain segment before the fault enters into the "big bend" area (Figures 1 and 3). . 
In most of the wells situated beyond $\sim 20 \mathrm{~km}$ from the San Andreas fault, the dominant $\mathrm{S}_{\mathrm{Hmax}}$ stress direction is consistent with previous observations of 'fault-normal' compression (Zoback et. al., 1987; Mount and Suppe, 1987, Castillo and Zoback, 1994). This remains the case even after the shallower data, some of which shows locally conflicting stress directions, is filtered out showing only stress observations deeper than $3 \mathrm{~km}$ (Figure 3c). This is most pronounced within the eastern portions of the Elk Hills Naval Petroleum Reserve (NPR) fields where the largest concentration of data was analyzed. Overall, these 'fault-normal' stress directions are geologically consistent with the compressional fold axes in the central valley which are shown as dashed lines in Figures 3a-c.

An important pattern that emerges considering the stress data within $20 \mathrm{~km}$ or so is that the $\mathrm{S}_{\mathrm{Hmax}}$ direction shows a pronounced rotation from northeast-southwest compression to nearly north-south becoming oblique to the trace of the San Andreas fault (Figures 3a-c). This pattern of 'fault-oblique' compression is observed on both sides of the fault to depths approaching $4 \mathrm{~km}$. As in the case with data located $20+\mathrm{km}$ from the fault, filtering to include $2+\mathrm{km}$ deep observations eliminates some of the inconsistent stress orientations which either show faultparallel compression or have a stress field that resolves left-lateral shear on San Andreas parallel planes. The implication is that these shallower measurements may be reflecting local stress anomalies and are likely not representative of a stress field associated with the San Andreas fault.

Interestingly, the perpendicular distance from the San Andreas fault where this stress transition from far-field fault-normal to near-field fault-oblique compression occurs appears to show a slight fault-strike dependence. Along the central and northwest sectors of our study area, stresses appears to rotate at about $20 \mathrm{~km}$ from the fault. However, near the 'big bend' area, there is a tendency for $\mathrm{S}_{\mathrm{Hmax}}$ to remain near fault-normal up to about $10 \mathrm{~km}$ from the fault (Figure 3ac). If the fault restraining character produced by the 'big bend' region contributes to the rotation in the stress field, one would expect the opposite variations along strike, namely, fault-oblique compression would be seen at further distances from the fault instead of $10 \mathrm{~km}$ or so. Perhaps along strike variations in fault rheology are contributing or controling the stresses (more on this later).

Probably the most detailed evidence showing the nature of this stress transition occurs within the Elk Hills NPR (Figure 4). In general, the Elk Hills NPR can be subdivided into two regionally distinct structures. The eastern half is characterized by a east-west trending anticlinal structure that changes to a more northwest-southeast orientation along the western half of the reserve. Along with this change in structure trend comes a gradual counter-clockwise rotation in $\mathrm{S}_{\mathrm{Hmax}}$ stress directions from northeast-southwest to a more northerly direction at the western extremes of the Elk Hills structure (Figure 4). Although there is a $\sim 7 \mathrm{~km}$ gap between the western Elk Hills NPR and the Cymric field further west, the transition from 'fault-normal' to 


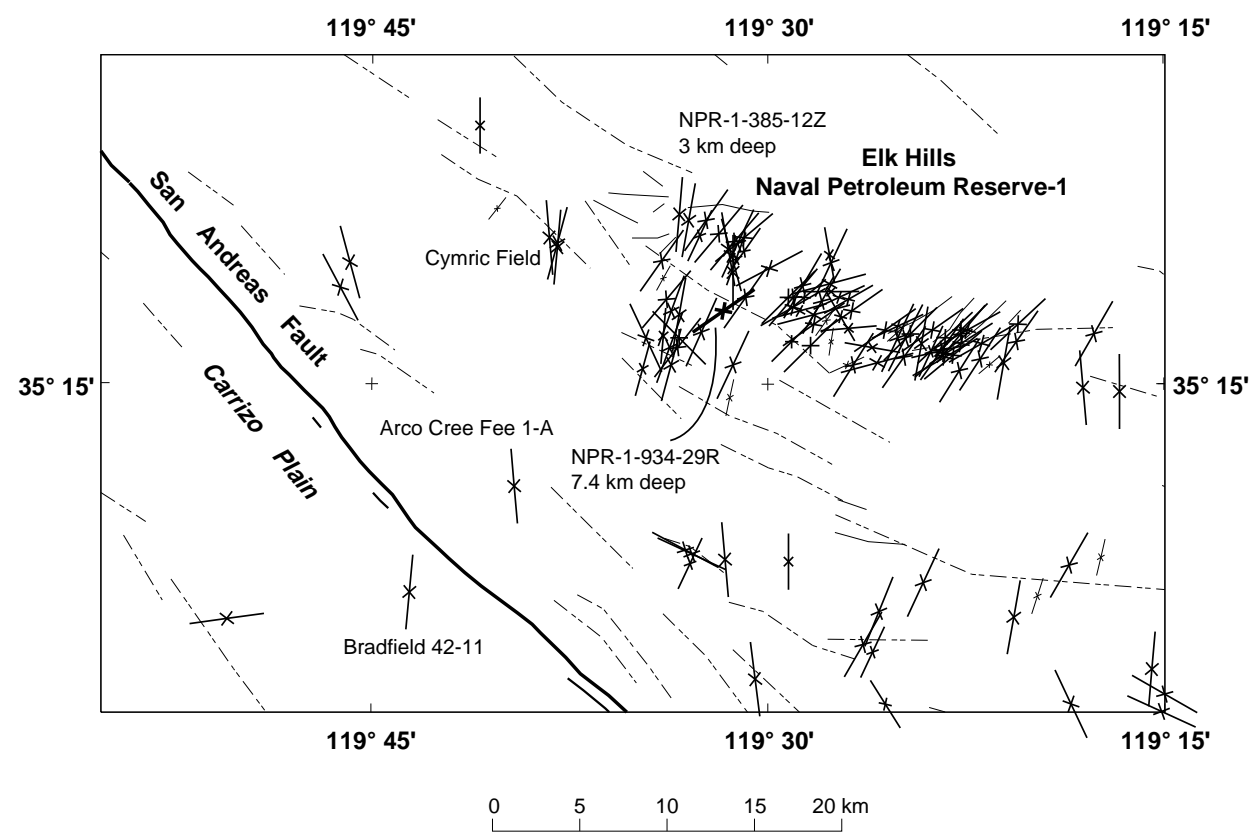

Figure 4 Detailed stress map within the Elk Hills Naval Petroleum Reserve spanning a distance of 15 - 30 $\mathrm{km}$ from the San Andreas fault. Stress symbols are the same as Figure 2. Stress observations within this range provides an excellent opportunity to examine details of the $\mathrm{S}_{\mathrm{Hmax}}$ stress transition from NE-SW to N-S compression. Over 70 wells analyzed in the Elk Hills area indicates that the apparent transition occurrs between 20 - $25 \mathrm{~km}$ from the San Andreas fault.

'fault-oblique' appears to be complete in the Cymric area since stress measurements in excess of $3 \mathrm{~km}$ deep show a well-pronounced north-south compression (Figure 4).

Distances beyond $20 \mathrm{~km}$ or so, the $\mathrm{S}_{\mathrm{Hmax}}$ directions are remarkably consistent with the trend of the fold axes which are sub-parallel to the San Andreas fault. In particular, one of the important arguments supporting the extrapolation of this stress field up to the plate boundary was that these fold axes remain sub-parallel to very near distances to the fault (Zoback et al., 1987; Mount and Suppe, 1987). Emerging from these new stress observations situated within $20 \mathrm{~km}$ of the fault, is an apparent inconsistency between the trend of these fold axes and the fault-oblique stresses (Figures 3-4). If the development of the SAF-parallel folds are a consquence of $\mathrm{S}_{\mathrm{Hmax}}$ acting nearly perpendicular to the structure, one is left with explaining the $\sim 45^{\circ}$ discrepency between the stresses and fold axes orientation. One possibility is that the folds orginally formed oblique to the fault trace in a classical wrench tectonics fashion but have since rotated as a result finite strain due to strike-slip motion on the San Andreas fault. There is some evidence in the Temblor range area that tentativley supports this hypothesis (personal communicaiton, Don Miller 1996, Stanford University). Alternatively, the folds may be the consequence of folding within the hanging wall of an updip propagating blind thrust which could be responding to near 
fault-normal compression, but at greater depths $(>10 \mathrm{~km})$. This depth-varying stress state at distances less than $20 \mathrm{~km}$ from the fault will be revisited later.

a)

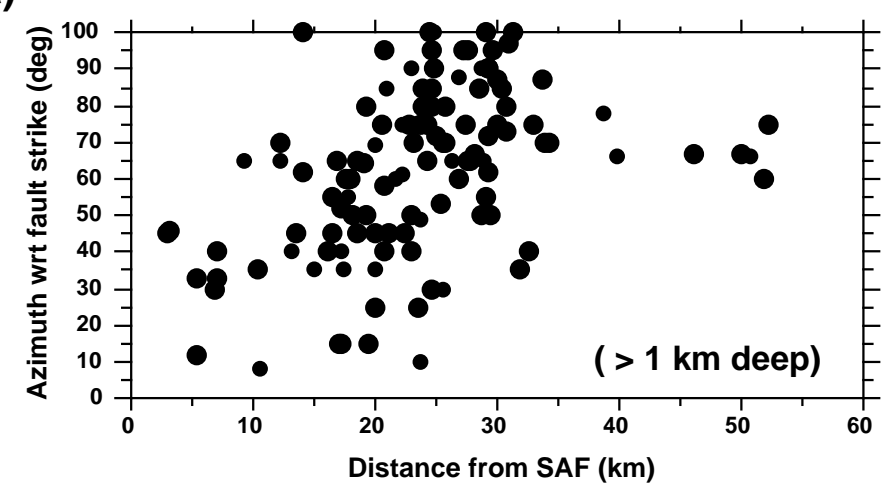

b)

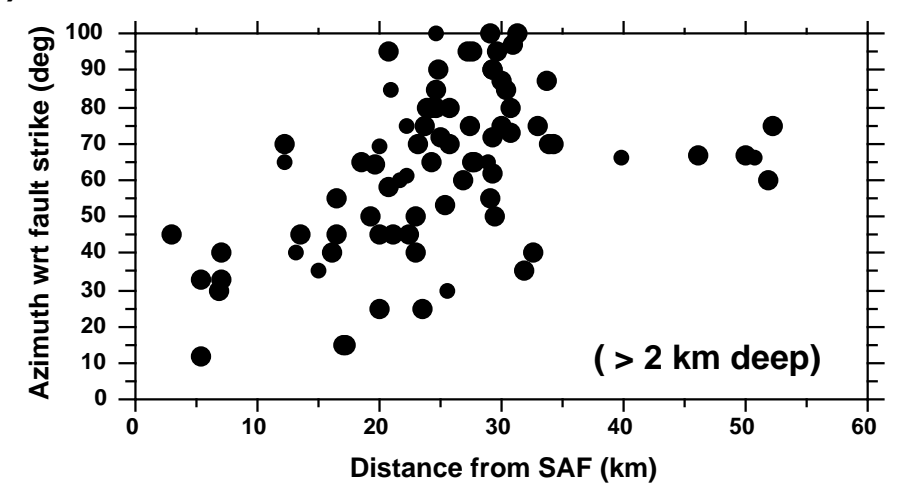

c)

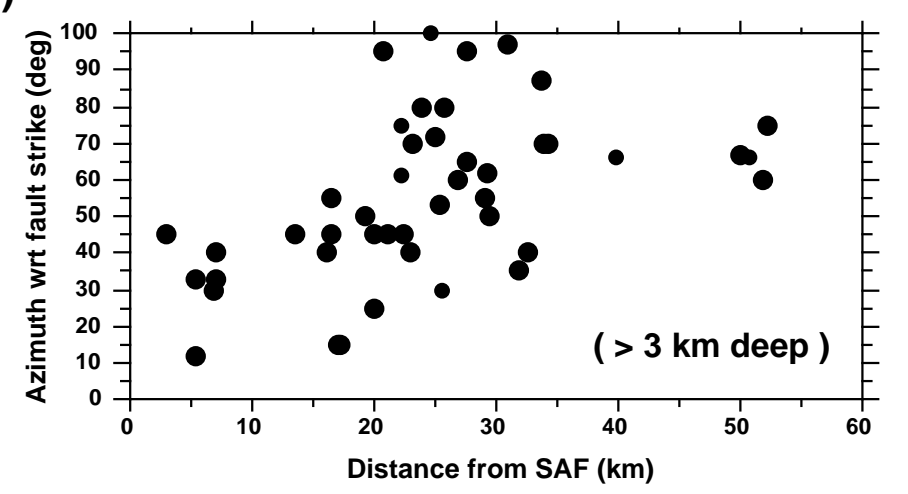

Figure 5 Stress versus Distance from the San Andreas fault. Azimuths are measured with respect to the strike of the fault $\left(\sim \mathrm{N} 40^{\circ} \mathrm{W}\right)$. Included are only data adjacent to the Carrizo plain segment but removed from the 'Big Bend' area in order to eliminate any geometric complications. a) Relative fault and stress azimuth for data $1 \mathrm{~km}$ or deeper. b) Relative fault and stress azimuth for data $2 \mathrm{~km}$ or deeper. c) Relative fault and stress azimuth for data $3 \mathrm{~km}$ or deeper. As was the case in Figure 2, data between $20 \mathrm{~km}$ and nearly $55 \mathrm{~km}$ from the San Andreas fault suggest that the fault can not ustain a great deal of shear stress. However, within $20 \mathrm{~km}$ or so of the fault, the relative azimuth changes from $\sim 75^{\circ}$ to about $30-45^{\circ}$ from the fault. 
There are four exceptional stress anamolies that cannot be explained by shallow filtering since they presist to depths in excess of $3 \mathrm{~km}$. One set of wells are located west of the SAF along the western margins of the Carrizo plain proper (Figure 3a-c). These three wells, situated about $12-15 \mathrm{~km}$ from the fault, show nearly fault-normal compression but with a small degree of left-lateral shear stresses on San Andreas parallel planes. That these anomalous stress directions presist to depth in excess of $3 \mathrm{~km}$ suggests strong local control. Based on an east-west crosssection that includes these wells (Davis et al., 1988), the observed stress-induced wellbore breakouts appears to be confined to an interval located between the east-dipping Morales thrust and White Rock thrust faults with east-west convergence beginning about $3 \mathrm{Ma}$. Between these wells and the SAF, are two wells; Carrizo Plain 1-16 (Figure 3) and Tenneco TWI Fee 1-33 (Figures $2 \mathrm{c}, 2 \mathrm{~d}$ and 3) that indicate a rotation to N-S compression or fault-oblique. Another exception includes a well situated on the east side of the fault showing nearly fault-parallel compression, which is consistent with a nearby shallow well also showing 'fault-parallel' compression (Figure 3a). Unfortunately there are no other wells within $10 \mathrm{~km}$ of these wells that would characterize how extensiveness this anomaly is in the area.

An alternate way of showing this transitional stress state is to plot stress orientations relative to the strike of the San Andreas fault for wells on both side of the fault (Figures 5a-c). Using a depth filtering scheme as in Figures 3a-c, this representation illustrates a depth consistent pattern of stress rotation at a distance of $\sim 20 \mathrm{~km}$ from the San Andreas fault. Although there is some noise in the data, as to be expected in 4-arm caliper data, the density of well coverage strongly suggests that dispite this apparent scatter in the data (which diminishes when only deeper data is considered), there is a well pronounced transition from fault-normal compression in the far-field to fault-oblique witihn $\sim 20 \mathrm{~km}$ from the San Andreas fault (Figure 5a-c).

There are far too few wells to test if this pattern of fault-oblique compression is still evident if only data in the $4+\mathrm{km}$ depth range is considered, however, Arco Cree Fee 1-A (Figures 2a-b, $3 \mathrm{c}$ and 4 ) shows a relative orientation of $33^{\circ}$ with respect to the fault at depths in excess of 3.9 $\mathrm{km}$ and about $5.4 \mathrm{~km}$ east of the fault. Beyond $20 \mathrm{~km}$ from the fault, most of the data deeper than $4 \mathrm{~km}$ lies between $55^{\circ}$ and $90^{\circ}$ relative to fault strike.

\section{Crustal Pore Pressure}

Nearly 300 wells were used to estimate crustal pore pressure adjacent to the San Andreas fault in the Carrizo plain area with a majority of the data from the San Joaquin basin. Pore

pressure estimates were based either on mud weight records or drill stem tests. There was agreement in those cases where both data types were used. A mud weight $\log$ is a recording of the density of drilling mud used during the drilling process, which in principal reflects, the formation pore pressure if there is a pressure balance between the borehole fluids and the 
formation pore pressure. This balance is important to maintaining stable drilling conditions by preventing 'washouts or bridging' (where under-balanacing causes failure of the rock formation and collapse of the borehole) and 'loss of circulation' (where severe over-balanacing causes fluids to flow into the formation at a rapid rate).

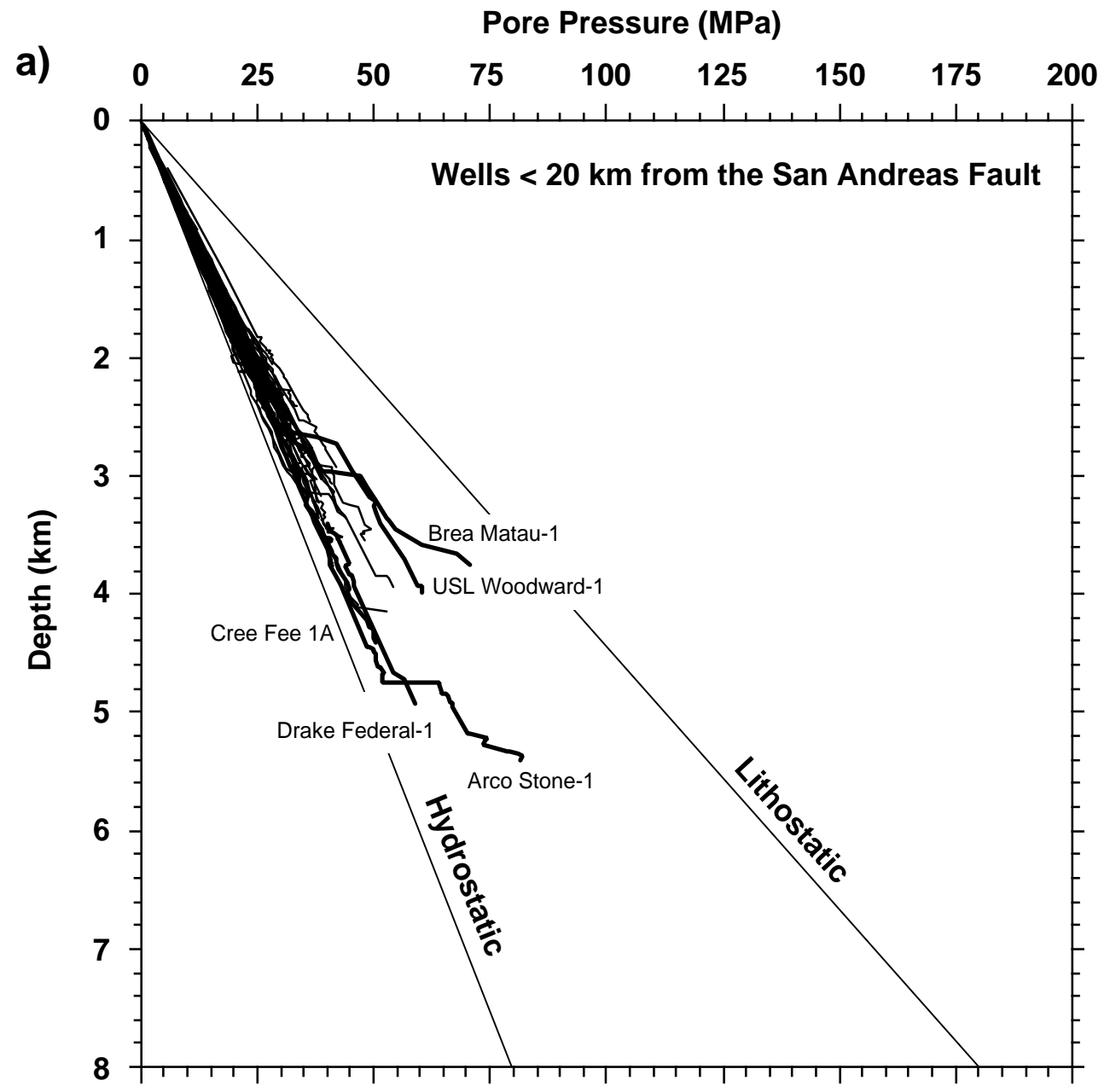

Figure 6 Pore Pressure estimates inferred from drilling mud weights and some drill stem tests. a) Wells situated less than $15 \mathrm{~km}$ from the San Andreas fault, b) wells situated greater than $15 \mathrm{~km}$ of the fault. Wells located within $15 \mathrm{~km}$ of the fault suggest crustal pore pressures to be near hydrostatic down to about $5 \mathrm{~km}$ depth. The elevated pore pressures from the Arco Stone-1 may indicate higher fluid pressures at greater depth. This is contrasted in b) where pore pressure increases steadily from a shallow depth $(2.5 \mathrm{~km})$ and approach $80 \%$ of lithostatic at a depth of about $7.5 \mathrm{~km}$. Elevated pore pressures far from the SAF locate well within the southern San Joaquin Valley where elevated pore pressures may be the result of diagenic dewatering processes associated with the rapid deposition of the sediments.

However, a degree of caution should be exercised when using mud weights to infer crustal pore pressure. In some cases, drilling muds are underbalanced to prevent accumulating a layer of mud clay on the borehole wall and inhibit the formation of drilling-induced hydraulic 
fractures. 


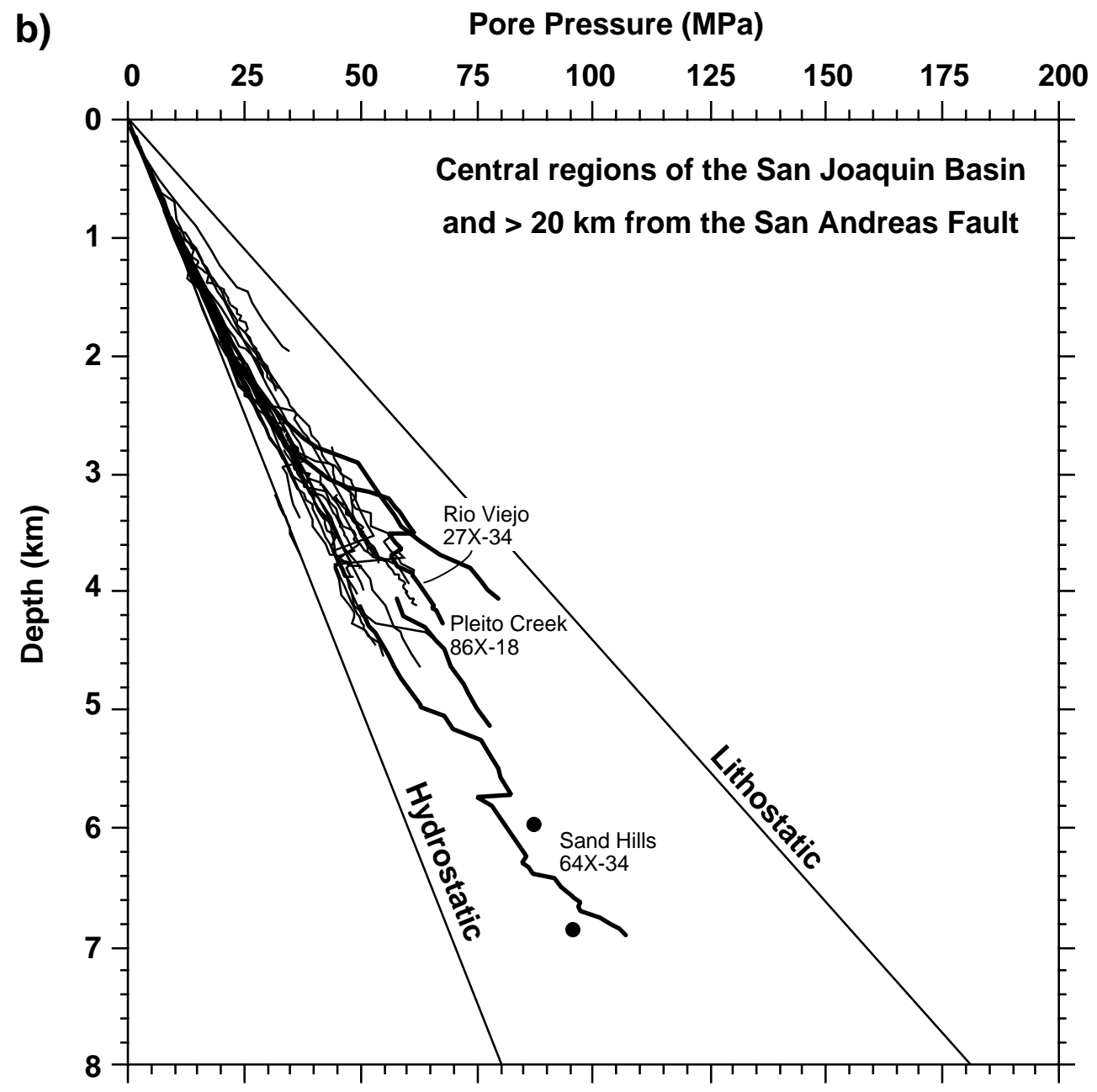

Figure 6 Continued 


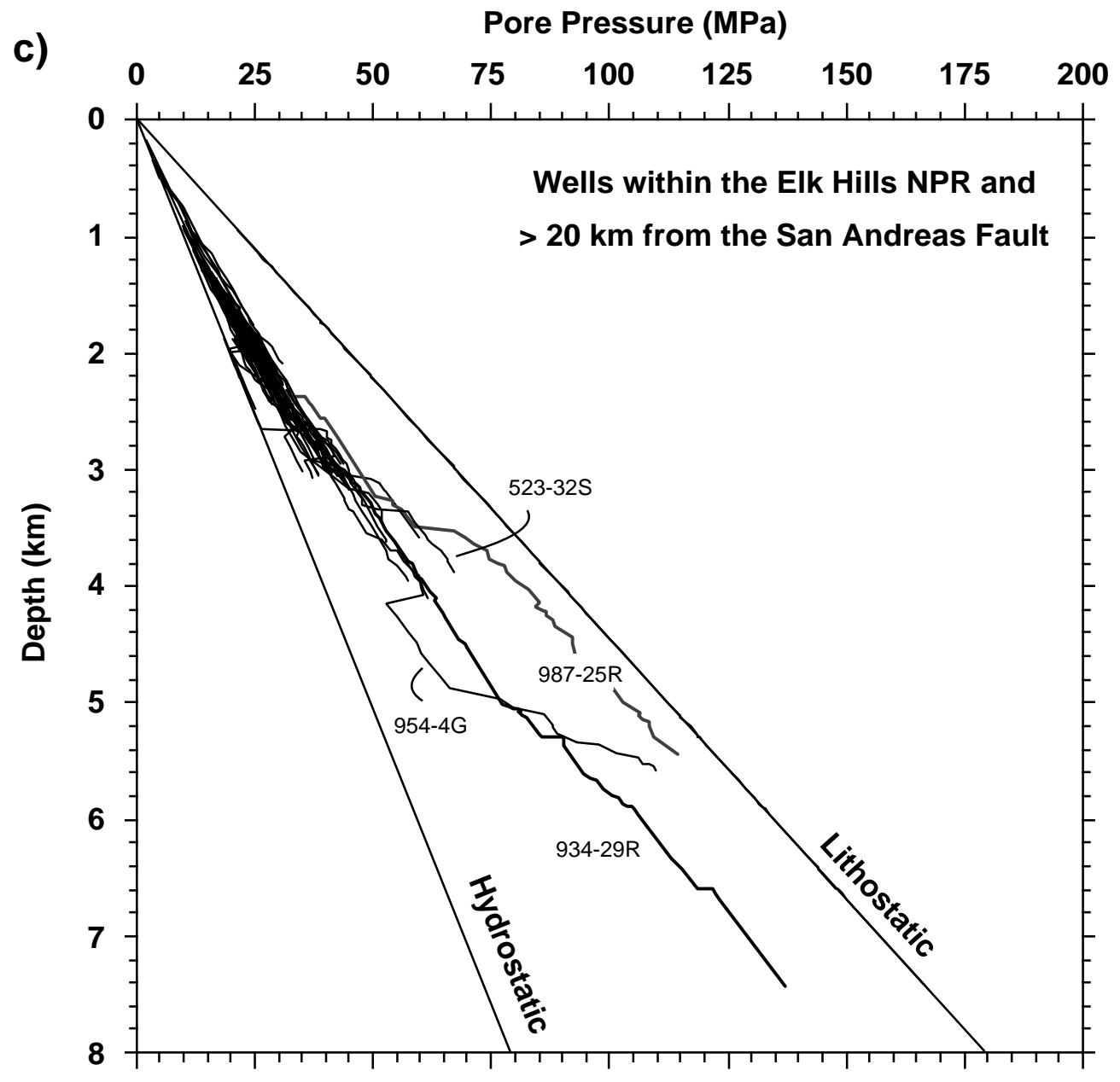

Figure 6 Continued 
Clay on the borehole walls reduces the response of the geologic/geophysical logs. Overbalanced wells prevents the development of wellbore breakouts, but can cause formation fluid invasion which also reduces the log response. The preferred method would be a series of drill stem tests which measure pore pressure within a specific interval, however, these tests are not frequently measured and if so, are conducted across hydrocarbon targeted intervals. Nonetheless, the abundance of wells used to map mud-weights in the Carrizo plain probably can be used as a rough descriminator to distinguish between areas of high or low pore pressure.

Because there seems to be a marked change in $S_{H m a x}$ directions at about 15-20 km from the SAF, we have regionally separated crustal pore pressure plots into wells located less than $20 \mathrm{~km}$ (Figure 6a) and wells greater than $20 \mathrm{~km}$ from the SAF (Figure 6b). For wells in the latter category, data has been further divided to examine details within the Elk Hills NPR (Figure 6c).

In general, the data indicates near-hydrostatic pore pressure to at least $5 \mathrm{~km}$ depth and within $20 \mathrm{~km}$ of the SAF. The Arco Cree Fee 1-A, located $5.4 \mathrm{~km}$ northeast of the fault indicates nearhydrostatic pore pressure to depths approaching $4.5 \mathrm{~km}$. These relatively low pore pressures are consistent with nearly all wells situated within $20 \mathrm{~km}$ of the fault. In contrast, the Arco Stone-1 well, the deepest well in the area, shows a significant increase in apparent pore pressure over a short interval below $5 \mathrm{~km}$. The other two wells that indicates a significant increase in apparent pore pressure are Brea Matau-1 and USL Woodward-1, both situated south-southeast of the SAF, near where the fault makes a bend.

The wells located $>20 \mathrm{~km}$ from the SAF indicate a significant increase in the apparent pore pressure, compared to wells near the fault. There is very little difference between both regions in the upper $3 \mathrm{~km}$, however, pore pressures rapidly increase to almost $60-80 \%$ of lithostatic. The drill-stem test conducted in Tenneco Sand Hills 64X-34 well are consistent with an average apparent pore pressure inferred from the mud weights. The gradual increase in pore pressure in the $7.4 \mathrm{~km}$ deep NPR $934-29 \mathrm{R}$ well begins with $\mathrm{P}_{\mathrm{o}} / \mathrm{S}_{\mathrm{V}} \sim 0.6$ at $4 \mathrm{~km}$ and increases to 0.8 at total depth.

Although speculative, the mud weight inferred increase in pore pressure below $5 \mathrm{~km}$ depth and within $20 \mathrm{~km}$ of the fault may increase further at greater depths, which would support the high pore pressure fault model after Byerlee (1990) and Rice (1992). However, as will be shown later, a rigorous interpreation of the Byerlee/Rice high pore pressure model would imply a 15-20 $\mathrm{km}$ wide San Andreas fault zone. This is probably unlikely, because the surface trace of the SAF is well confined to a kilometer or so zone with no clear evidence of additional SAF-parallel strike-slip faults within $20 \mathrm{~km}$ of the main trace. Lower pore fluid pressures are required adjacent to the elevated fault-zone fluid pressures, however, the data indicates the opposite with high apparent crust pore pressures beyond $20 \mathrm{~km}$ of the San Andreas fault. 


\section{Frictional Faulting Theory for Estimating Stress Magnitudes}

Estimates of the principal stress magnitudes in the vicinity of the Carrizo Plain segment of the San Andreas fault were made using $S_{\mathrm{hmin}}$ magnitudes from hydrofrac treatments in the San Joaquin Valley, and $\mathrm{S}_{\mathrm{Hmax}}$ from Frictional Faulting theory using Byerlee's law (Byerlee, 1979) and a Mohr-Coulomb failure criteria (Jaeger and Cook, 1979). Estimates of the third and vertical component of the stress tensor is presumed to be equivalent to the vertical lithostatic load (i e., $S_{\mathrm{v}}$ ).

\section{Minimum Principal Stress Magnitudes ( $\left.S_{\text {hmin }}\right)$}

Hydraulic fracturing treatments in the Cymric Deep Gas Field situated about $18 \mathrm{~km}$ from the SAF and the Elk Hill NPR provided reasonably consistent $S_{\mathrm{hmin}}$ magnitudes to depth approaching $3 \mathrm{~km}$. The exploration wells drilled close $(<10 \mathrm{~km})$ to the San Andreas fault are normally abandoned when the well fails to produce any signs of hydrocarbons. Therefore, none of the near-field wells have any information regarding stress magnitudes from hydraulic fracturing treatments, since such treatments are generally used during enhanced oil recovery efforts.

Four hydraulic fracturing treatments from the Cymric field were utilized in this study. The relatively close spacing between wells and the consistency between estimates of $\mathrm{S}_{\mathrm{hmin}}$ magnitudes (Figure 7a) in this area compared to other well sites in the San Joaquin Valley suggest that $S_{\mathrm{hmin}}$ this field may be representative of the stress state, at least within $18 \mathrm{~km}$ of the SAF. Without additional stress information close to the fault, we will assume that the trend in $\mathrm{S}_{\mathrm{hmin}}$ magnitudes observed in Cymric field may be representative of the stress state close to the fault.

The relative stress magnitudes in the Cymric field, as in many other wells in the San Joaquin Valley, are such that $S_{h \min }<S_{\mathrm{v}}$. The average $S_{\mathrm{hmin}} / \mathrm{S}_{\mathrm{v}}$ "frac" ratio shown in Figure $7 \mathrm{a}$ is about 0.65 , which is also consistent with other observations throughout the San Joaquin Valley, at least below 2 km (Personal Communications, Bill Minner, Pinnacle Technologies Inc.). The possible stress states consistent with the observed $S_{\mathrm{hmin}} / \mathrm{S}_{\mathrm{v}}$ ratio are either strike-slip or normal faulting stress regimes. Based on the observed strike-slip and reverse faulting seen within the San Andreas fault system and within the adjacent crust, we can rule out the possibility of a normal faulting stress regime Another reason why a normal faulting stress state can be discounted is that the stress concentrations resulting from such a stress state could not support the development of wellbore breakouts that are so pervasive throughout the Central Valley.

There are anomalous areas in the San Joaquin Valley where the frac ratio $S_{\mathrm{hmin}} / \mathrm{S}_{\mathrm{V}}$ approaches unity, but these place are restricted to shallow depths $(<500 \mathrm{~m})$ in the diatomite rocks within the Lost Hills and Belridge fields (Wright et al., 1996). In these situations, tiltmeter 
arrays deployed during hydraulic fracturing treatments detect near-horizontal hydofracs propagating away from the wellbore. Deployment of these tiltmeter arrays for deeper fracs (> $2 \mathrm{~km}$ ) in other parts of the Central Valley indicate a near-vertical hydraulic fracture implying that the minimum principal stress is approximately horizontal.

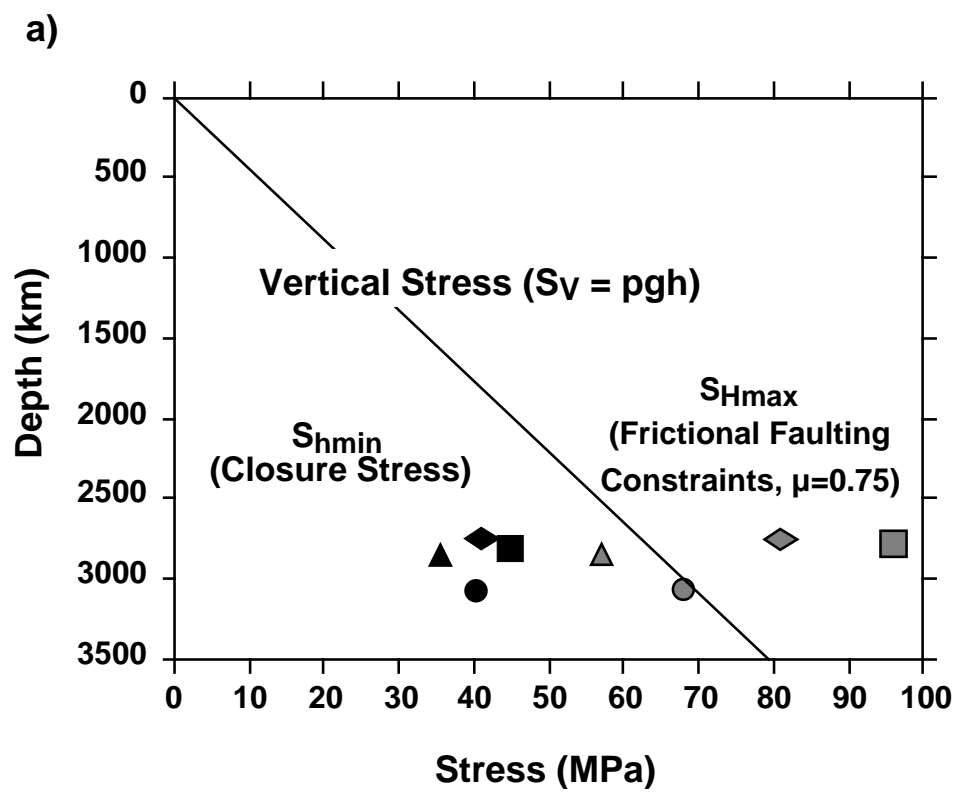

Figure 7 Possible strike-slip stress state within $15 \mathrm{~km}$ of the San Andreas fault along the Carrizo Plain segment. Stress states correspond to a depth of $3 \mathrm{~km}$ which is about the average observation depth of wellbore breakouts showing a consistent rotation from NE-SW to N-S near the fault. a) Estimates of the minimum principal stress magnitude $\left(S_{h m i n}\right)$ inferred from hydraulic fracturing treatments in the Cymric field located $18 \mathrm{~km}$ east of the San Andreas fault, b) The inferred stress profiles rely on the assumption that hydraulic fracture gradients observed in the Cymric wells located near $(\sim 18 \mathrm{~km})$ the San Andreas fault are representative of the $S_{h m i n}$ gradient. The vertical load, $S_{v}$, is based on an average rock density of $2300 \mathrm{~kg} / \mathrm{m}^{3}$. Possible $\mathrm{S}_{\mathrm{Hmax}}$ values range from $\phi=1.0\left(\mathrm{~S}_{\mathrm{Hmax}}=\mathrm{S}_{\mathrm{V}}\right)$ to a limiting factor of $\phi=0.38$, assuming frictional faulting contraints and a coefficient of friction of $\mu=0.6$ (Jeager and Cook, 1979). c) Equivalent 2-D Mohr Circles to the stress states shown in b) but extrapolated to a depth of $15 \mathrm{~km}$.

\section{Maximum Principal Stress Magnitudes $\left(S_{\text {Hmax }}\right)$}

Probably the single most difficult component of the stress tensor to quantify is the maximum horizontal stress $\left(S_{H \max }\right)$. Where a $S_{h \min }$ is well constrained using several pressure cycles of a hydraulic fracture treatment or 'extended leakoff tests', $\mathrm{S}_{\mathrm{Hmax}}$ can be estimated assuming that subsequent pressure cycles have already exceeded the tensile strength of the rock formation and the fracture has propagated several borehole radii away. Without, this information, we will appeal to an alternative method for constraining $S_{\text {Hmax }}$ utilizing the observed style of wellbore failure. Given we can estimate a $S_{\mathrm{hmin}}$ profile from the data collected in the Cymric field and elsewhere in the Central Valley, we explore a range of possible $\mathrm{S}_{\mathrm{Hmax}}$ values using a Mohr- 

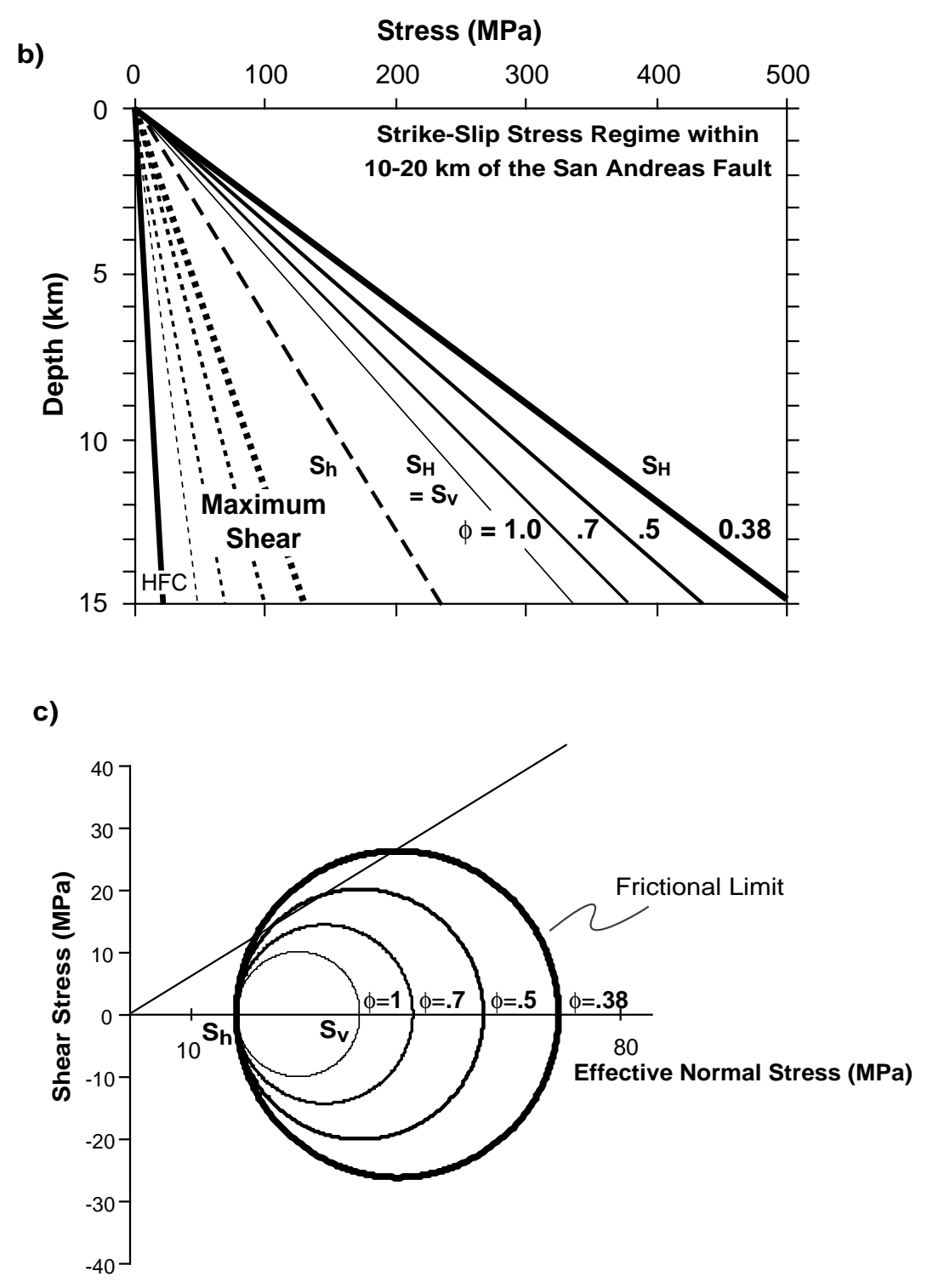

Figure 7 Continued

Coulomb failure criteria (Jaeger and Cook, 1979) which places constraints on the ratio of maximum and minimum effective stresses in terms of the strength of the crust.

The formulation is based on a failure criterion first proposed by Coulomb (1773) that states that the ratio of the shear $(\tau)$ and the normal stresses $\left(\sigma_{n}\right)$ applied on a particular plane at failure is equivalent to the coefficient of friction $(\mu)$, namely;

$$
\frac{|\tau|}{\sigma_{\mathrm{n}}}=\mu
$$


In 2-Dimensions, the shear and normal stresses can be expressed in terms of the principal stresses and the angle $(\beta)$ the plane makes with $S_{1}$,

$$
\begin{gathered}
\sigma_{\mathrm{n}}=\frac{1}{2}\left(\mathrm{~S}_{1}+\mathrm{S}_{3}\right)-\frac{1}{2}\left(\mathrm{~S}_{1}-\mathrm{S}_{3}\right) \cos (2 \beta) \\
\tau=\frac{1}{2}\left(\mathrm{~S}_{1}-\mathrm{S}_{3}\right) \sin (2 \beta)
\end{gathered}
$$

If we substitute (2) into (1) and find the angle $\beta$ that maximizes the equality, we come up with the following relationship, after Jaeger and Cook (1979)

$$
\frac{\left(S_{1}-P_{o}\right)}{\left(S_{3}-P_{o}\right)} \leq\left[\left(\mu^{2}+1\right)^{\frac{1}{2}}+\mu\right]^{2}
$$

This important relationship states that the ratio of the effective principal stresses is limited by the frictional strength of the crust. If this ratio exceeds the frictional limit, slip will occur on optimally oriented faults in order to relieve the shear stresses. Because the coefficient of friction has been extensively measured in a variety of rock types under a wide range of confining stresses and found to vary slightly between 0.6 and 1.0 (e.g., Byerlee, 1979), this Mohr-Coulomb failure criteria provides a powerful technique to constrain the limits of stress magnitudes if either the maximum or minimum principal stress can be determined. This failure criteria has been confirmed with field stresses measurements using hydraulic fracturing methods in seismically active areas (e.g., McGarr, 1980; Zoback and Healy, 1984, 1992; Barton et. al., 1988; Vernik and Zoback, 1992; Hickman et al., 1996). In these cases, $S_{H \max }$ measurements were consistent with the frictional limit (Equation 3), implying a fault to be in frictional equilibrium with the surrounding crust.

A relatively restrictive range of possible stress tensors are used to describe the upper crust in frictional equilibrium. In order to completely investigate all tensor possibilities, we explore those stress tensors where $\mathrm{S}_{\mathrm{Hmax}}$ is less than the frictional limit defined in Equation (3), but keeping $S_{h m i n}$ and $S_{v}$ (vertical stress) the same. One way to describe a systematic variation in $\mathrm{S}_{\mathrm{Hmax}}$ is to consider the relative stress magnitudes to be such that $\mathrm{S}_{1}>\mathrm{S}_{2}>\mathrm{S}_{3}$, and use the relation after Angelier (1979;

$$
\phi=\frac{S_{2}-S_{3}}{S_{1}-S_{3}},
$$


where $\phi$ varies from 0 to 1 . For a strike-slip faulting stress regime (i.e., $S_{H \max }>S_{v}>S_{h m i n}$ ), Anderson's faulting theory (Anderson, 1951) defines $\phi=\left(\mathrm{S}_{\mathrm{V}}-\mathrm{S}_{\mathrm{hmin}}\right) /\left(\mathrm{S}_{\mathrm{Hmax}}-\mathrm{S}_{\mathrm{hmin}}\right)$. When $\phi=0$, relative stress magnitudes are such that $S_{\mathrm{V}}=S_{\mathrm{hmin}}$, or a transitional stress state that can support both strike-slip and reverse faulting. When $\phi=1$, stress magnitudes are such that $S_{V}=S_{H \max }$ which is also a transitional stress state but between strike-slip and normal faulting. An example of these possible stress states are shown in Figure 7b-c.

Upper limits for $\mathrm{S}_{\mathrm{Hmax}}$ magnitudes were derived assuming frictional faulting theory, a coefficient of friction, $\mu=0.75$, and near-hydrostatic pore pressure. This upper limit was determined at a depth of $3 \mathrm{~km}$, corresponding to the average depth of wellbore breakouts analyzed in this study. If we use an average $S_{\text {hmin }}$ value, as seen in the Cymric field, in Equation 3 to estimate the frictional limit of $\mathrm{S}_{\mathrm{Hmax}}$ at hydrostatic pore pressure conditions, we find that $\phi=0.4$ (Equation 4). Since we do not have independent evidence to constrain $\mathrm{S}_{\mathrm{Hmax}}$ values, we cannot rule out the possibility that $\mathrm{S}_{\mathrm{Hmax}}$ could be less than the frictional limit defined by Equation 3, and as low as $\mathrm{S}_{\mathrm{Hmax}}=\mathrm{S}_{\mathrm{V}}(\phi=1)$. The relative stress magnitudes and corresponding shear stresses are shown in Figure 7c. For fixed values of $S_{h \min }$ and $S_{\mathrm{v}}$, any decrease in $S_{H \max }$ magnitudes corresponds to a decrease in shear stress (i e., a decrease in the size of the Mohr circle (Figure 7c) Also shown in Figure 7b is the maximum shear stress that would satisfy the heat-flow constraint (Lachenbruch and Sass, 1980).

\section{Shear Stresses Along the Carrizo Plain Segment of the San Andreas Fault}

Having detailed stress orientation data in the SAF near-field as well as the surrounding crust (Figures 3 and 4) and plausible stress magnitude information, provides an unprecendeted opportunity to examine how shear stresses vary along SAF-parallel planes as a function of distance from the fault. Using Equations $2 \mathrm{a}$ and $2 \mathrm{~b}$, and the Mohr-Coulomb failure criteria (Jaeger and Cook, 1979) shear failure could occur when,

$$
\tau-\mu\left(\sigma_{\mathrm{n}}-\mathrm{P}_{0}\right)>0
$$

where $\left(\sigma_{\mathrm{n}}-\mathrm{P}_{\mathrm{o}}\right)$ is the effective normal stress, $\tau$ is the applied shear stress, and $\mu$ is the coefficient of friction, where we use $\mu=0.6$ consistent with Byerlee (1979). Using the relative stress orientation data shown in Figure 5, the Mohr-Coulomb shear failure criteria along SAF-parallel planes were determined using estimates of stress magnitudes discussed above. The results are also presented in Figure 8 showing variations in shear stress as a function of distance from the fault. The vertical bars reflect the range of possible $S_{H \max }$ magnitudes ranging from $S_{\mathrm{Hmax}}$ $=$ frictional limit (high $\phi)$ and $\mathrm{S}_{\mathrm{Hmax}}=\mathrm{S}_{\mathrm{V}}(\phi=1)$. The results indicate a strong tendency for the Mohr-Coulomb shear stresses to increase within $20 \mathrm{~km}$ of the fault. Considering data farther 
than $20 \mathrm{~km}$ from the fault, the Mohr-Coulomb shear failure criteria is markedly negative implying the likelihood for shear failure is very low. Although the data would appear to be noisy in the upper $1 \mathrm{~km}$ or so, the propensity for shear failure increases irrespective of filtering efforts to depth-filter the data (Figure 8 ). This increase in shear stress in the vicinity of the SAF is more pronounced if near-lithostatic pores pressures are considered, although, appealing to these elevated pressures are not necessary to promote failure.
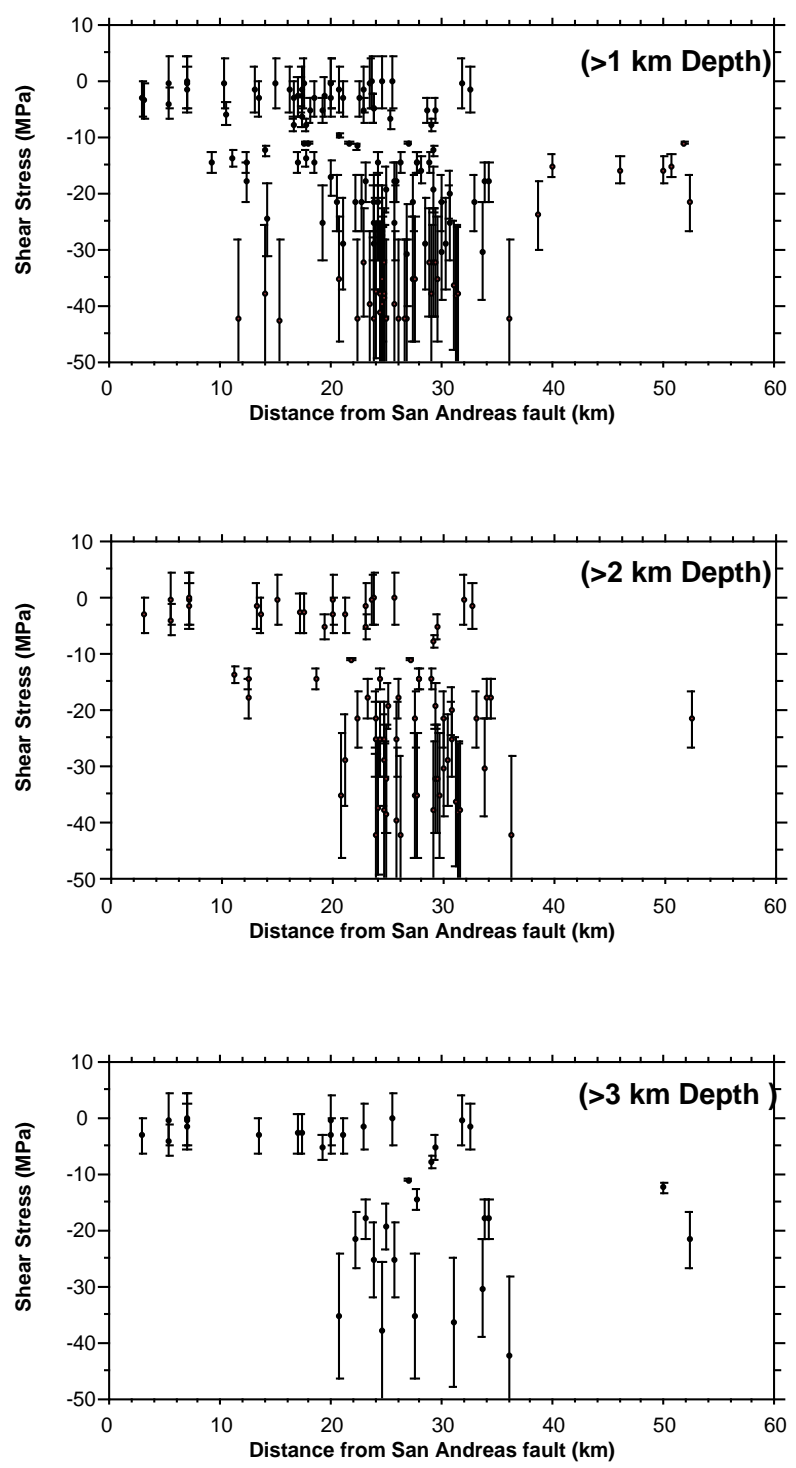

Figure 8 Mohr-Coulomb failure criteria (shear stress) using the possible stress states at $3 \mathrm{~km}$ depth shown in Figure 6 and the stress direction profile data shown in Figure 3. The failure criteria as a function of distance from the San Andreas fault considering only data with observations a) $\geq 1 \mathrm{~km}$ deep, b) $\geq 2$ $\mathrm{km}$ deep, and c) $\geq 3 \mathrm{~km}$ deep. The vertical limits indicated by the bars represent the bounding limits of stress states considered in Figure 6 with $\phi$ ranging from 1.0 to 0.38. The important issue is that the conditions for shear failure along SAF parallel planes (Mohr-Coulomb failure criteria >0) markedly increases within $20 \mathrm{~km}$ of the San Andreas fault. 


\section{Non-Uniform Fault Strength}

Probably the most profound observation that emerges from this study is that the Carrizo plain segment of the San Andreas fault appears to sustain a relatively higher level of shear stress compared to other neighboring segments, based on stress directions. Although our stress magnitudes information is not as well constrained as our stress directions, the relatively high stress differentials seen at $15+\mathrm{km}$ from the fault would have to decrease markedly near the fault to produce a low shear stress environment along the SAF, and still satisfy the observed faultoblique orientations and the apparent lack of a heat-flow anomaly. This same low stress differential produces insufficient stress concentrations around the borehole wall that could not support the widespread development of wellbore breakouts as seen throughout the San Joaquin Valley.

A comparison between stress direction data observed along the Carrizo plain segment and three other segments (i.e., San Francisco Bay Area, central California between San Juan Bautista and Parkfield, and Mojave desert) suggests that the Carrizo plain may be unique. Although the density coverage along the three comparison segments is less than the Carrizo plain area (Figure 9), the current data along the San Francisco, Central California and Mojave segments still suggest that these segments have low resolved shear stresses (Figure 10). The San Francisco Bay Area is complicated because the San Andreas Fault System widens considerably from several kilometers in Central California to 70-100 km between the Bay Area and the Mendocino Area (e.g., Wallace, 1990; Castillo and Ellsworth, 1992). The dominant stress indicators in this area are earthquake focal mechanisms adjacent to the San Andreas fault proper, Hayward, and Calaveras faults (Zoback et al., 1987; Oppenheimer et al., 1988), together showing $\mathrm{S}_{\mathrm{Hmax}}$ to be at high-angles to the fault system (Figures 9 and 10a).

A similar conclusion is evident along the Central California segment, where good well coverage further supports the hypothesis of a "weak" fault (Figure 10b). The weak fault hypothesis is well supported in Central California because of the abundance of stress-induced wellbore breakouts and earthquake focal mechanisms (Coalinga and Kettleman Hills earthquakes), and the SAF-subparallel fold axes. The Central California segment has been a classic example of fault-normal compression, although we are still not clear of the fault weakening mechanim(s). Perhaps an extreme response to this weakening mechansim might result in a fault being unable to sustain any shear stresss, which could apply to this segment based on the creeping behavior of the SAF or very regular earthquake recurrence intervals (Bakun and Lindh, 1985; Bakun and McEvilly, 1984).

Prior to this study, the well coverage along the Carrizo plain segment was similar to Central California, indicating that the fault may also be "weak". Clearly, the collection of additional data 


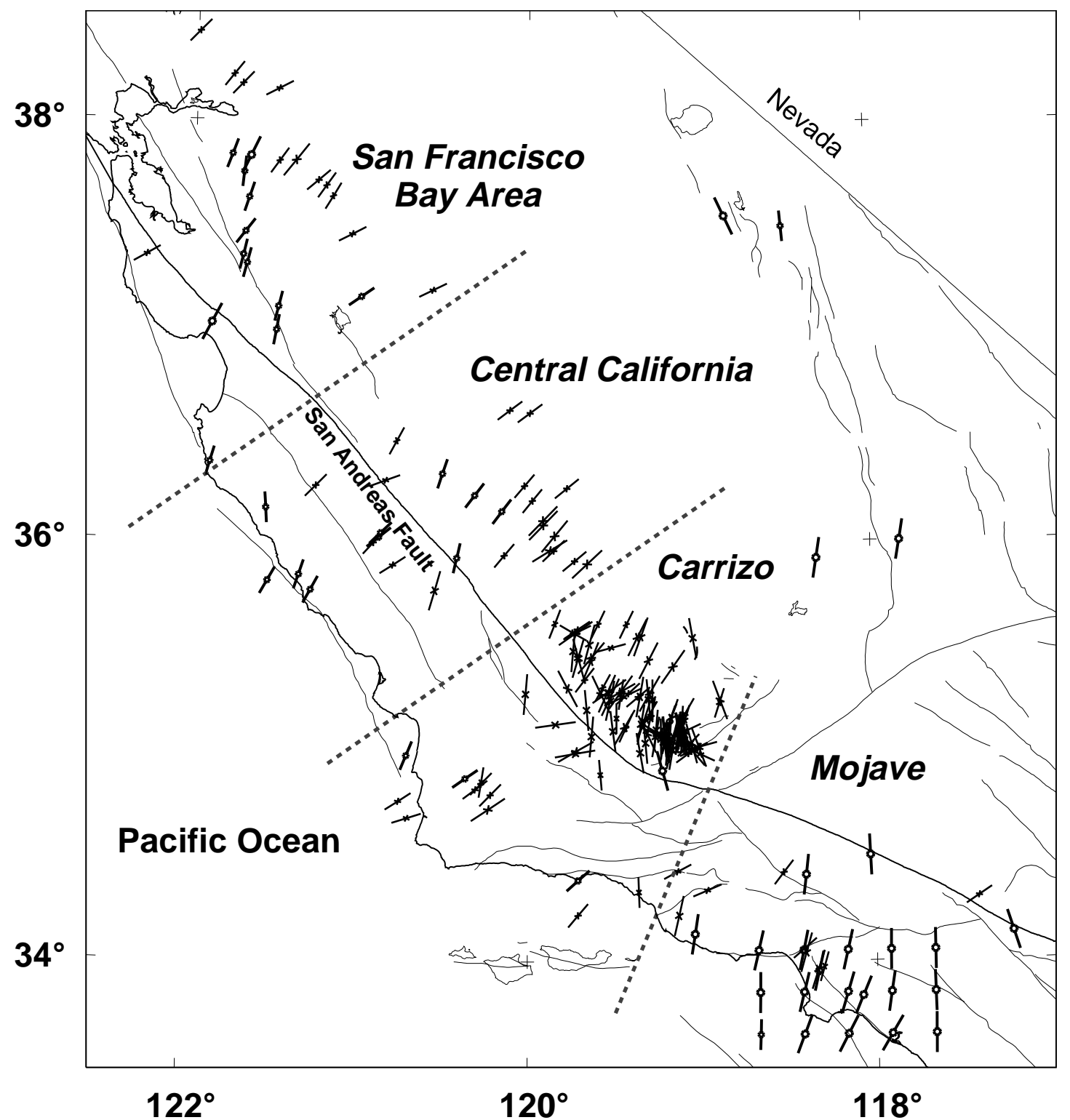

Figure 9. Stress map of the San Andreas fault between the San Francisco Bay Area and the Mojave desert segments. The inward facing arrows correspond to the maximum principal stresses ( $\mathrm{S}_{\mathrm{Hmax}}$ ) and the open circles are stress indicators inferred from focal mechansim stress inversions or composites. The SAF has been subdivided into the San Francisco Bay Area, Central California, Carrizo plain, and Mojave Desert segments to illustrate the stress state with respect to the fault orientation shown in Figure 10.

within $20 \mathrm{~km}$ of the fault in the Carrizo plain area provided the detailed information to characterize the near-field stress state, of which this report is central (Figure9 and 10c).

The Mojave segment stress coverage is dominated by earthquake focal mechanism inversions showing $\mathrm{S}_{\mathrm{Hmax}}$ to be oriented about $65-75^{\circ}$ to the fault (Figure 10d). There are two stress 
indicators from wells situated within $5 \mathrm{~km}$ of the fault (Hickman et al., 1988; Stock et al., 1988) showing inconsistent results. One of the stress measurements from these shallow $(\sim 1 \mathrm{~km})$ wells indiate a $\mathrm{S}_{\mathrm{Hmax}}$ direction of about $45^{\circ}$ with respect to the fault (Stock et al., 1988).

Stress directions adjacent to the SAF along the San Francisco Bay Area, Central California, and the Mojave desert are essentially identical with $\mathrm{S}_{\mathrm{Hmax}}$ oriented about $65-85^{\circ}$ with respect to the fault. One possible consequence steming from the difference between the "fault-oblique" stress state in the Carrizo plain and the "fault-normal" stress state in the Mojave desert, is that there should be an appreciable heat-flow anomaly in the Carrizo plain area, assuming frictional heating is occurring.
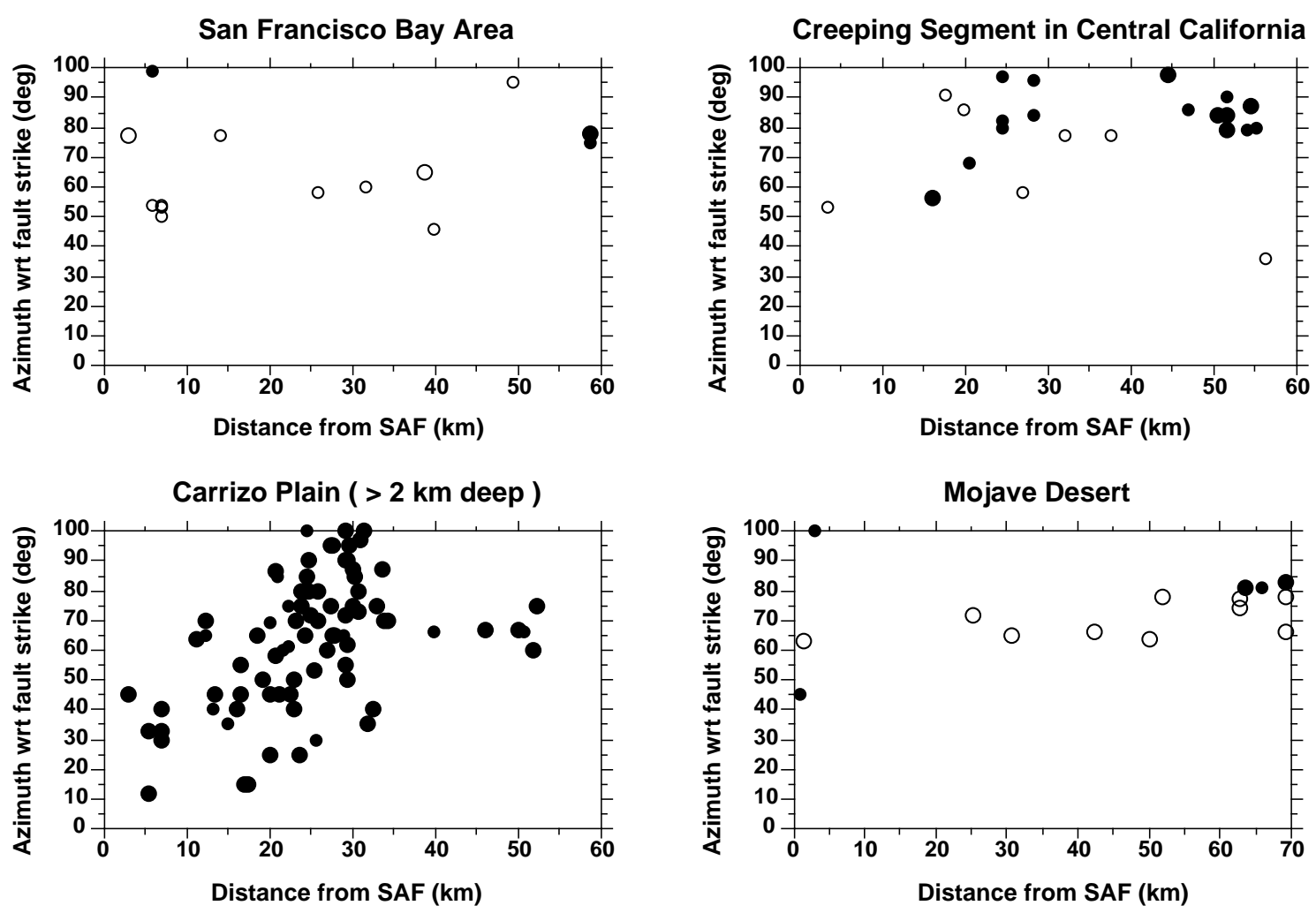

Figure 10 Comparison of stress states associated with four different segments of the San Andreas fault shown in a). Stress orientations relative to the strike of the San Andreas fault and as a function of distance to the fault for b) San Francisco Bay Area segment, c) Creeping segment in central California, d) Carrizo Plain segment ( $\geq 2 \mathrm{~km}$ deep), and e) Mojave Desert segment. SHmax stress indicators include those inferred from wellbore breakouts (solid) and earthquake focal mechanisms (open). Although the stress rotation along the Carrizo Plain segment is well deliniated with near-field data, the other segments do not appear to show any significant rotation within $20 \mathrm{~km}$ of the San Andreas fault, suggesting higher shear stress along the Carrizo Plain.

The lack of a pronounced heat-flow anomaly over the SAF within the Mojave segment clearly indicates a low-shear stress fault segment (Figures 11 and 12). However, the heat-flow data for the Carrizo plain area does not completely rule out the possibility of an anomaly because 
of the step-wise increase in heat-flow when crossing the SAF from east to west (Figure heat). This step-wise increase may be the thermal effect associated with the recent uplift of the Coast Ranges juxtaposd to the relatively cool Great Valley (Figures 11 and 12).

\section{Modeling}

Preliminary modelling efforts explaining the transition in the stress field from fault-normal to fault-oblique is being performed using a 2D finite element code (TECTON) and a 3-D dislocation code. One of the important issues that any modelling approach needs to address is whether the stress transition is a temporal feature related to the earthquake cycle. For instance, will the present-day fault-oblique stress orientation return to fault-normal immediately following the next major earthquake, if we assume that the stress drop associated with the event was complete? The appealing aspect of this hypothesis is that it would explain the development of the SAF-parallel fold axes in response to an apparent stress change to northeast $\mathrm{S}_{\mathrm{Hmax}}$ direction immediately following the major earthquake.

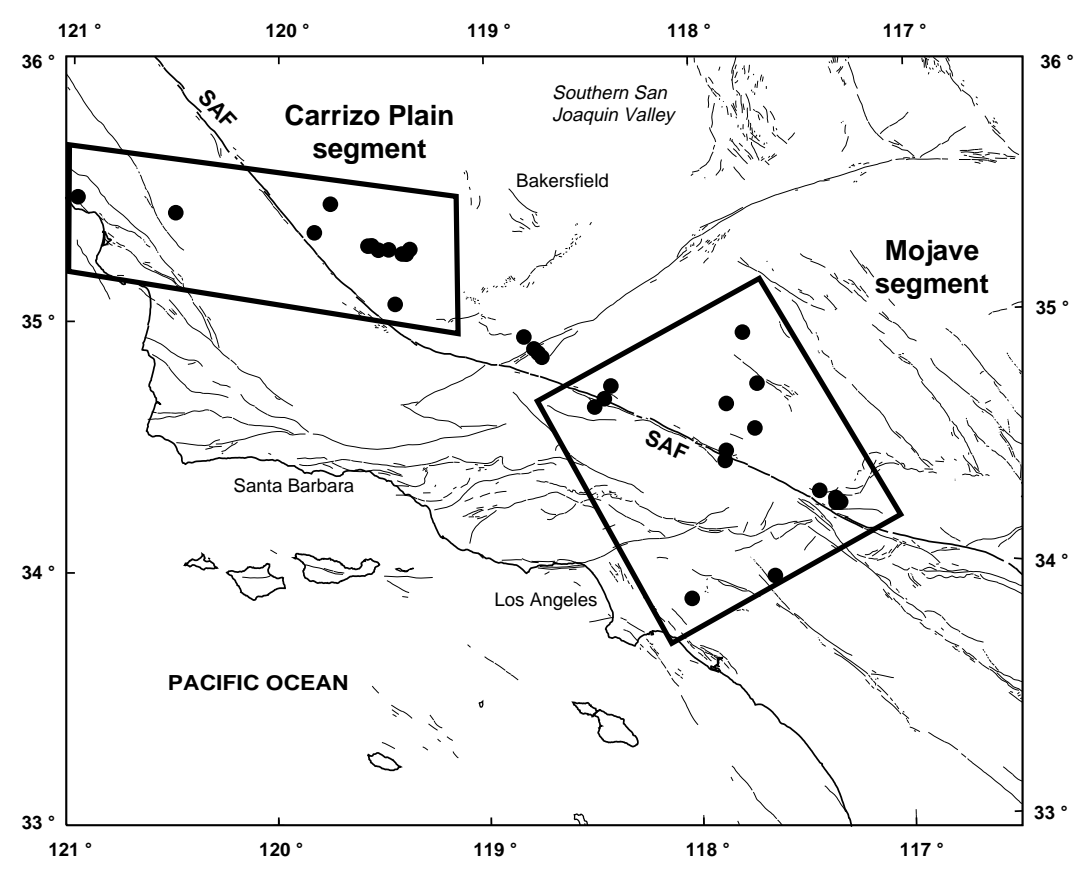

Figure 11. Location map of heat-flow measurements adjacent to the Carrizo plain and Mojave segments of the San Andreas fault (after Lachenbruch and Sass, 1980).

We've attemped a very generalized simulation of this process by imposing an equivalent slip history along the ductile and aseismic portion of the fault during several earthquake cycles, and examined the resultant stress field in the upper locked section immediately following the earthquake. We used a brittle-ductile rheology shown in Figure 13a using different heat-flow 
values consistent with the scatter of values seen in the San Joaquin Valley (Figures 11 and 12). The rheology model was designed to allow for a smooth and realistic transition from the elastic 
a)

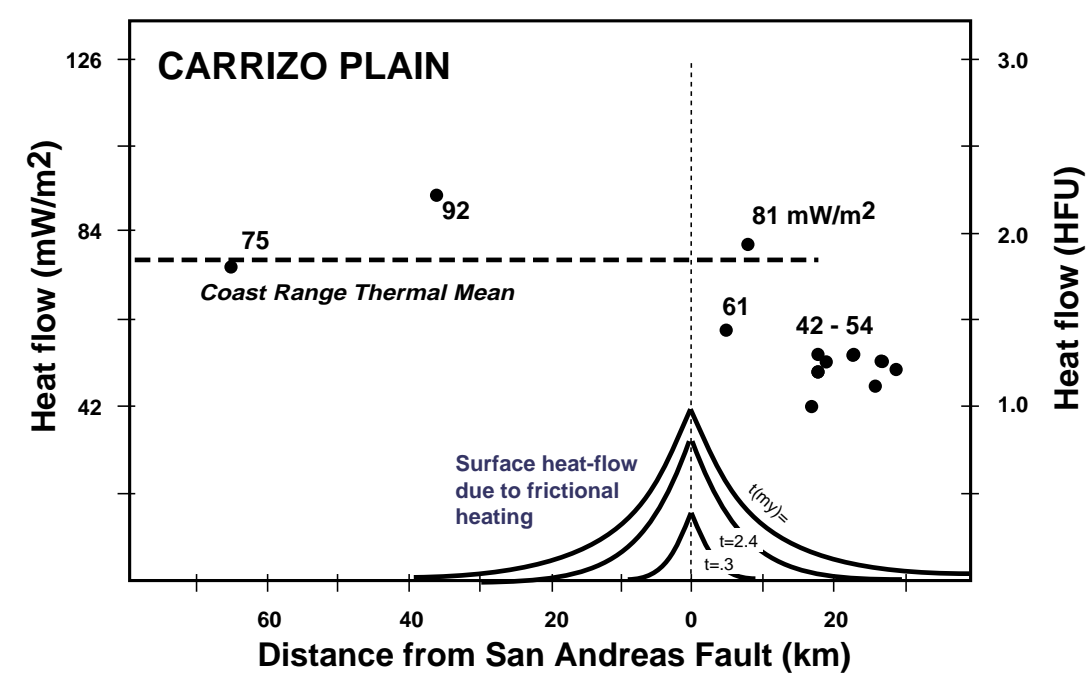

b)

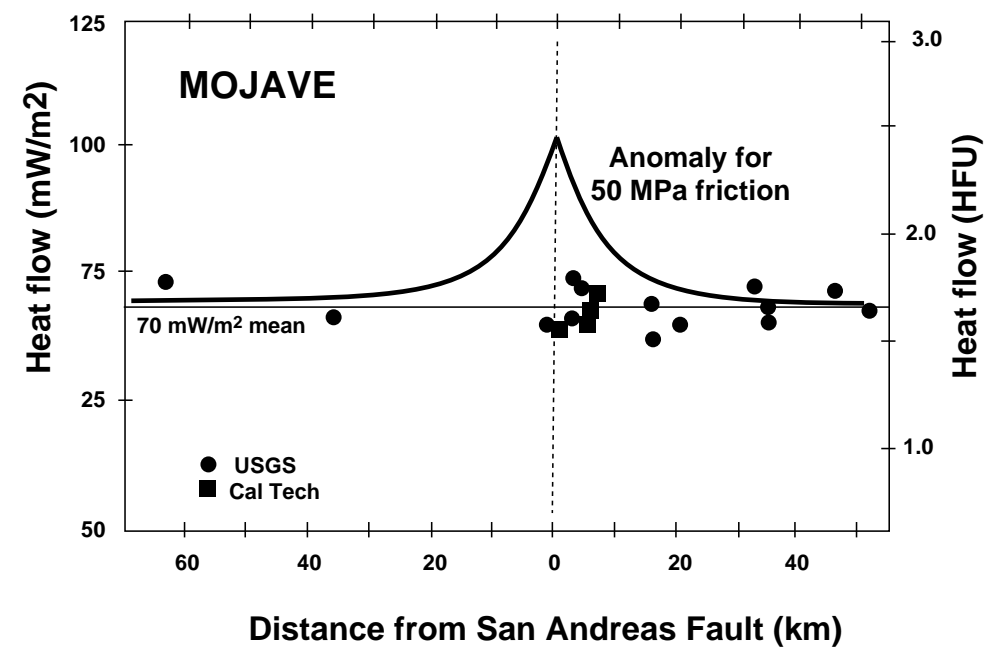

Figure 12 Comparison of heat-flow data from the Carrizo Plain and Mojave Desert segments. a) Carrizo Plain heat-flow, and b) Mojave desert heat-flow plotted with respect to distance from the San Andreas fault. The step increase in heat-flow across the San Andreas fault in Carrizo may not be a attributed to the fault, but rather to a possible thermal boundary between the recently uplifted (and warm) Coast Ranges to the west and the relatively cool crust in the Central Valley. This is contrasted in the Mojave desert area where there is no marked heat-flow anomaly and the stress data suggests low shear stress (Figure 10). After Lachenbruch and Sass (1980) 
a)

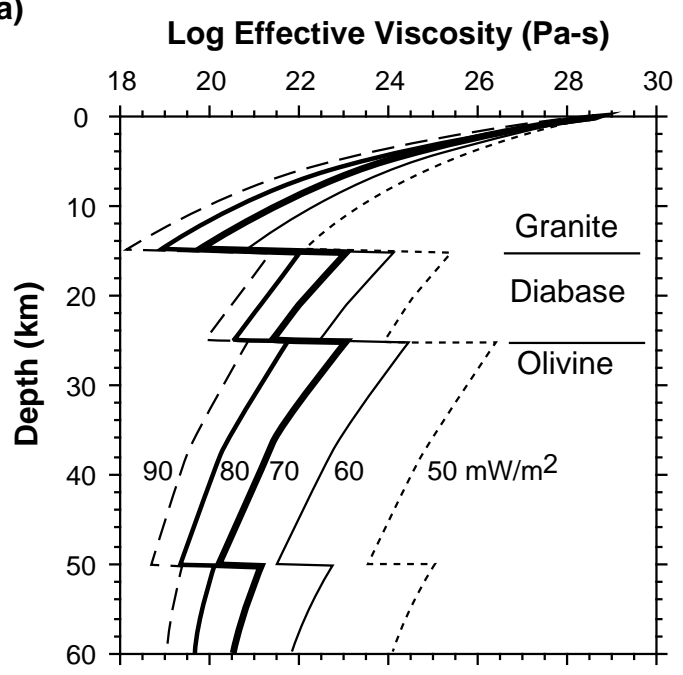

b)

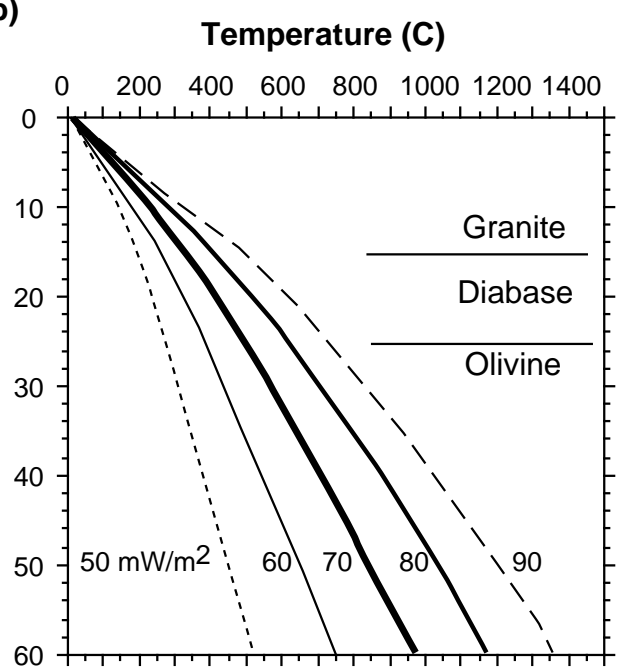

Figure 13. Earth model paramters used in the finite element based on the range of heat flow measurements seen in the San Joaquin Valley. a) Temperature profiles inferred from different heat-flow observations shown in Figures 11 and 12. b) Effective viscosity profile used in the finite element model. Note the gradual transition between the elastic and viscoelastic layers, with the viscosity decreasing 3 orders of magnitude. This transition acts to avoids the stress singularity imposed by the abrupt elastic and viscoelastic boundary, but more importantly, uses model rheologies that are more geophysically plausible.

granite to the plastic diabase/olivine regions. The effective viscosities at this transition decreases by about 3 orders of magnitude so as to avoid any stress singularities near the base of the locked section of the fault (Figure 13a). Using this finite element model, we imposed a 200 and 300 year recurrence interval along a fault slipping at $35 \mathrm{~mm} / \mathrm{yr}$, below the locking depth of about 14 $\mathrm{km}$ and monitored the shear stress at a depth of $3 \mathrm{~km}$ (average depth of stress orientation data).

Our modelling tested whether the 200-300 year strain accumulation between earthquakes was sufficient to increase the shear stresses and therefore rotate the $\mathrm{S}_{\mathrm{Hmax}}$ direction to the presentday configuration. Assuming the far-field $\mathrm{S}_{\mathrm{Hmax}}$ direction is fault-normal and stress magnitudes consistent with the industry data, the resultant superposition between the accumulated shear stresses and the far-field stresses near the end of the cycle are insufficient to rotate the stresses to fault-oblique. Figure 14 serves to illustrate that for the in-situ stress directions to rotate between major earthquakes, the difference in the far-field horizontal stresses must be extremely small or comparable in magnitude (i e., $\mathrm{S}_{\mathrm{H} \max } \sim \mathrm{S}_{\mathrm{hmin}}$ ). Therefore, our conclusion is that the present-day stress state is long-term and does not rotate from fault-oblique to fault-normal as a consequence of a total stress drop earthquake.

Although the temporal shear stress accumulation is insufficient to rotate the local stress field, there does appear to be a stress concentration near the fault that reduces to about $50 \%$ of its peak value at about 15-20 km from the fault (Figure 14a). Similar results have been obtained using 2- 
D finite element and 3-D dislocation codes, in that the high shear stress concentration occurs within $15-20 \mathrm{~km}$ of the fault. The stress concentrations and stress directions could be reproduced within the area straddling the fault, however, the stress magnitudes were an order of magnitude less than expected based on the magnitudes estimates inferred from the industry data. Extrapolating the industry data to regions close to the fault may not be warranted, in which case, the model boundary conditions need to be modified. A more accurate approach, which we are exploring, is to model the fault rheology separate from the surrounding crust and impose stressboundary conditions on the fault instead of treating the fault and surrounding crust as homogeneous. A similar approach of using stress boundary conditions along the fault and displacement boundary conditions along the sides of the model were employed by Lyzenga et al., (1991), however, the models tested were generalized and short of performing a sensitivity analysis.

a)

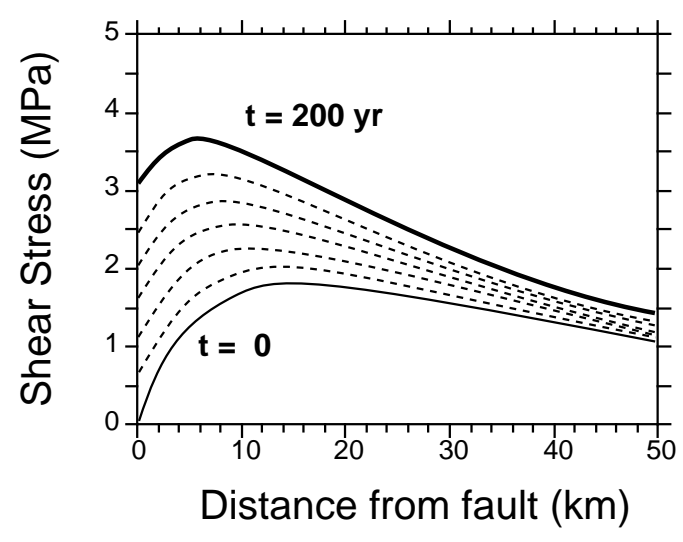

b)

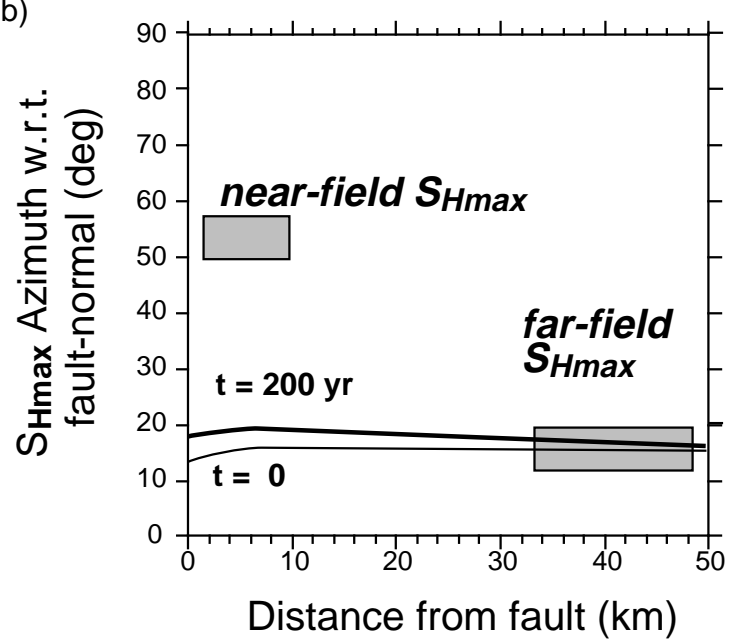

Figure 14 Shear stress loading at a depth of $3 \mathrm{~km}$ over the earthquake cycle. a) Shear stresses induced by aseismic slip below the locaking depth of $\sim 14 \mathrm{~km}$ at a slip rate of $35 \mathrm{~mm} / \mathrm{yr}$ over a 200 year earthquake cycle, plotted as a function of distance from the fault. b) Superposition of the induced shear stresses and the far-field stress state inferred from hydraulic fracturing in the Cymric field (indicated by the shaded box $>30 \mathrm{~km}$ from fault and oriented $\sim 15^{\circ}$ wrt the fault). The near-field relative stress orientations from the observed stress directions are indicated by the upper shaded box $(<20 \mathrm{~km}$ from fault and oriented $\sim 55^{\circ}$ wrt the fault). The thin and thick lines correspond to the supperposition of the induced shear stresses and the far-field state for $\mathrm{t}=0 \mathrm{yr}$ (immediately following the earthquake) and $\mathrm{t}=200 \mathrm{yr}$ (immediately preceeding the earthquake). Note the lack of a rotation in the stress direction from "fault-oblique" before the earthquake to "fault-normal" after the earthquake.

\section{Implications}

The observed transition in $\mathrm{S}_{\mathrm{Hmax}}$ directions from fault-normal to fault-oblique in the nearfield regions of the San Andreas fault presents an intriguing problem in our efforts to understand the physical mechanisms leading to earthquake nucleation and propagation. The in-situ stress 
analysis presented in this study reflects new infomation about the possible spatial variability in fault strength between the different segments of the San Andreas fault, which is essential for understanding the dynamics of faulting and the earthquake process. Interestingly, our results add a new "twist" to our current knowledge of the state of stress along this major plate boundary, and does so by adding a few more unresolved issues.

For instance, a mechanism for explaining the San Andreas "weak" fault model has been to appeal to elevated fault zone pore pressues (Byerlee, 1990; Rice, 1992). Our generalized estimates of the crustal pore pressure inferred from mud weight drilling information does not fully support or discount a high fault zone pore pressure model. Based on the coverage of data collected a kilometer-wide fault zone with elevated pore pressure cannot be completely ruled out. The Byerlee/Rice model cannot be fully supported by our data because none of the wells actually penetrated the SAF proper, and the data closest to the fault indicate near-hydrostatic pore pressures but only to depths approaching $5 \mathrm{~km}$ (Figure 6). Elevated pore pressures may exist at greater depth and within the $15-20 \mathrm{~km}$ stress transition zone, however, these extremely wide fault-zone dimensions would imply that the principal displacement zone for this plate boundary would be equally wide. The remarkably narrow $(<1 \mathrm{~km})$ surface expression of the San Andreas fault in the Carrizo plain is evidence against such a wide fault zone since we are not seeing a banded shear zone 10-40 km wide.

The fault-oblique stress orientation adjacent to the Carrizo plain segment strongly suggests that the segment may be "strong" and able to sustain relatively high shear stresses. However, if frictional heating during the faulting process is still operative, the step-wise heat-flow profile shown in Figure 12 does not conclusively demonstrate a "strong" fault character, but it is suggestive. This step-wise profile could be explained by a thermal response to the recent uplift of the Coast Ranges during the past $5 \mathrm{Ma}$ or so, in which case the difference in heat flow across the fault may be due to the juxtaposition between the warm Coast ranges and the relatively cool San Joaquin Valley. The Heat-Flow Group at the U.S. Geolgical Survey is currently exploring the possibility of re-entering idle wells or 'holes of opportunity' in the San Joaquin Valley, particularly near the San Andreas fault.

Another possibilty may be that frictional sliding generates little heat because of several dynamic weakening mechanisms associated with the earthquake rupture and propagation processes. These include a reduction in the normal stresses or dilatational opening immediately preceeding the propagation front (Brune, 1993); acoustic fluidization (Melosh, 1979, 1996); and granular debris weakening (Scott, 1996). These various mechanisms have not been field tested since they describe processes that occur at seismogenic depths and require deep in-situ observations. 
One of the strongest arguments supporting a fault-normal stress orientation immediately juxtaposed to the San Andreas fault have been the Pliocene-recent fold axes oriented sub-parallel 


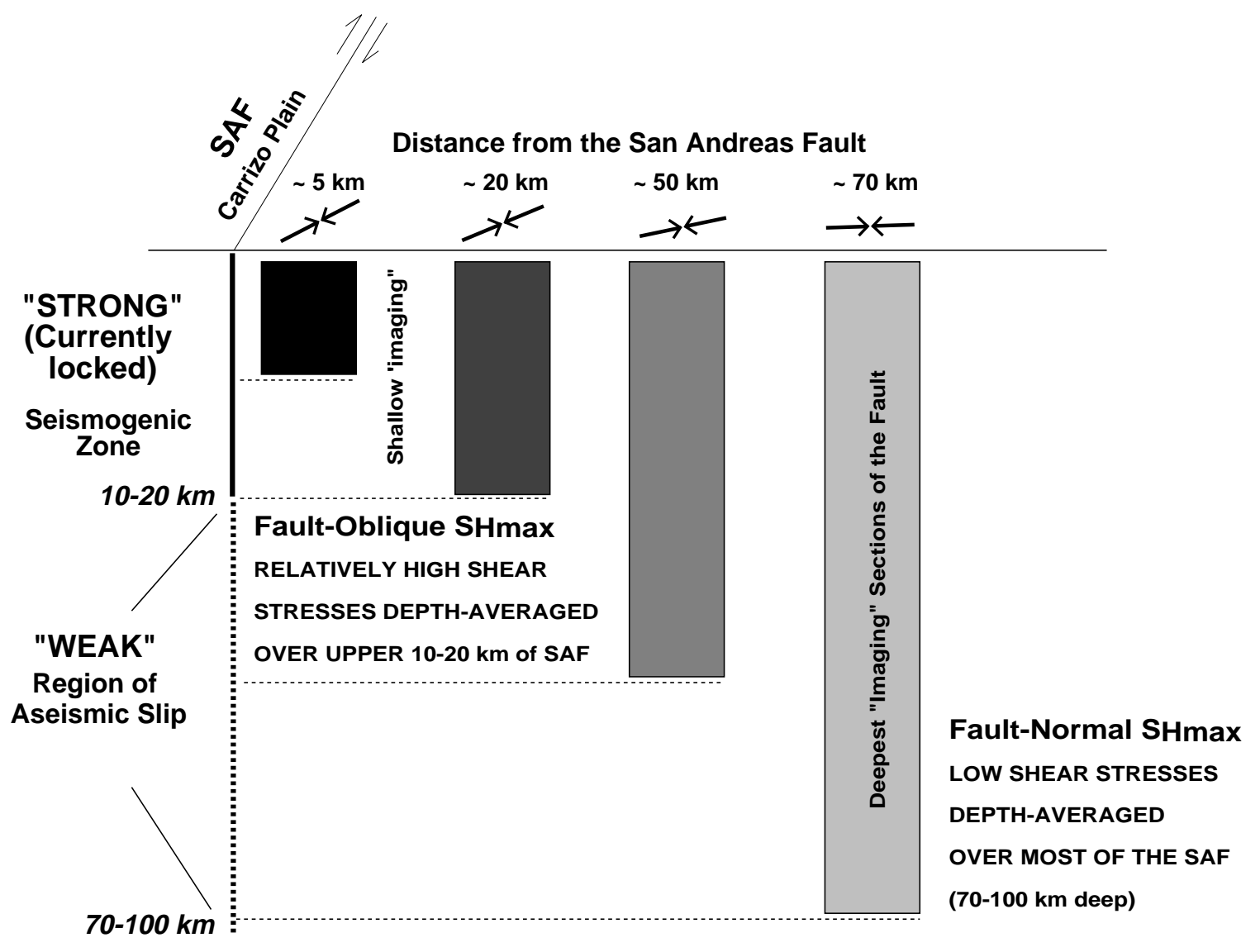

Figure 15. Conceptual fault strength versus depth model illustrating how the distance-varying stress state may be representative of stresses seen at specific depths along the active portions of the San Andreas fault. In-situ stress measurements collected in the far-field, which show 'fault-normal' SHmax directions, may be imaging the stress state depth-averaged over a depth comparable to the distance of the measurement. In the far-field case, fault can be considered weak when averaged over the entire depth of the plate boundary, since most of the fault, situated below the seismogenic zone, is slipping asesimically with very little resistance to shear. Within the near-field, the stresses observed may be imaging the shallow portions of the fault comparable to the distances. For the 'fault-oblique' stress state seen within $15-20 \mathrm{~km}$ of the fault, the relativley high shear stresses resolved on the fault would imply that the upper portions of the fault can sustain significant shear stresses. 
to the plate boundary. The apparent discrepency between these fold axes and the fault-oblique stress orientation is difficult to reconcile. From our modelling, it would appear that the presentday stress state is long term, implying a stress orientation which is inconsistent with the fold axes (assuming the fold axes reflect a structural response due to a stress direction oriented perpendicular to the folds). This incompatibility between the fold axes and fault-oblique stress state may be the result of deep seated folding driven by slip occurring along low-angle and SAFsubparallel faults associated with NE-SW convergence. This would again appear to be inconsistent with the observed stress state, unless the stress directions situated at depths greater than our wellbore observations but within $\sim 20 \mathrm{~km}$ from the SAF are subject to NE-SW compression. Although appealing, because these blind thrust faults have not been remotely imaged with seismic or been seismically active in recent times, we have no means of support a fault-oblique to fault-normal transition with depth at distances less than $20 \mathrm{~km}$ from the SAF.

Preliminary modelling would also suggest that the region straddling the SAF, where the "fault-oblique" stress directions are observed, may be representative of the average SAF stress state but restricted to depths comparable to the distance where the transistion occurrs. At distances out to $60-70 \mathrm{~km}$ from the fault, the observed "fault-normal" stress direction may indicate an average stress state over the lithospheric thickness of the fault. If so, inferrences of the stress state operative along the seismogenic portions of the SAF may only come from in-situ stress measurements taken within $15-20 \mathrm{~km}$ of the SAF.

\section{Conclusions and Recommendations}

The San Andreas fault along the Carrizo plain segment appears to be characterized by a $\mathrm{S}_{\mathrm{H} \max }$ near-field stress orientation that is fault-oblique $\left(30-45^{\circ}\right)$ to the SAF. This $\mathrm{S}_{\mathrm{H} \max }$ orientation reflects a stress transistion from fault-normal to fault-oblique occuring between 15-20 $\mathrm{km}$ from the SAF. Supporting evidence includes stress-induced wellbore breakouts measured using 4-arm caliper dip meter logs in nearly 150 wells. These wells which reached depths approaching $7.5 \mathrm{~km}$, locate between 3 and $60 \mathrm{~km}$ on either side of the San Andreas fault. Data from wells located beyond $20 \mathrm{~km}$ or so indicates a NE-SW S $\mathrm{S}_{\mathrm{max}}$ direction, or "fault-normal" which is consistent with previous observations (Zoback et al., 1987; Mount and Suppe, 1987; Castillo and Zoback, 1994). Observations of this transistion to nearly N-S S $\mathrm{H}_{\max }$ direction, or "fault-oblique" within $20 \mathrm{~km}$ of the SAF appears to represent a long-term stress state and not one that fluctuates within the earthquake cycle. However, stress indicators showing a fault-oblique direction is inconsistent with the SAF-parallel fold axes. If these folds are deep-seated, their development may be the consequence of motion within the hanging wall of a deep blind thrust sub-parallel to the SAF, but accommodating NE-SW convergence in response to a deeper NESW $\mathrm{S}_{\mathrm{Hmax}}$ direction. There is no extensive subsurface imaging of deep-seated low-angle blind 
thrust faults that may be responsible for the folding mapped at the surface, although, a proposal submitted to the Continental Dynamics Division of National Science Foundation to investigate such processes and manifestations as transcompressional strain partitioning in the Carrizo plain area .

One of the primary motivations for conducting this in-situ stress anslysis was to characterize the possible drill sites for the San Andreas Fault Zone Drilling Project, recently proposed to National Science Foundation, U.S. Geological Survey, Department of Energy, and the International Continental Drilling Program (e.g., Hickman et al., 1995; Zoback et al., 1995; Hickman et al., 1994). Although there are many industry wells drilled in the vicinity of the Carrizo plain segement, which is one of the candidate drill sites, future efforts should focus on attaining available well data adjacent to other sites such as the Parkfield and Mojave segments. To better constrain our understanding of stress magnitudes along the SAF, acquiring industry hydraulic fracturing data should be a part of that effort.

Previous modelling of the stress field adjacent to the SAF has never before included data of the nature presented in this study. These near-field stress observations provides an unprecedented opportunity to model the strength of the fault in a depth-dependent manner. The limitations of the modelling attempted in this study demonstrates that the rheology of the fault zone must be treated differently from the surrounding crust. Code development using stress boundary conditions along the locked portions of the SAF is currently being investigated.

The importance of obtaining detailed measurements of the principal stress magnitudes ( $\mathrm{S}_{\mathrm{Hmax}}$ and $\mathrm{S}_{\mathrm{hmin}}$ ) within the near-field regions of the San Andreas fault is critical. The San Andreas Fault Zone Drilling Project will certainly contribute a great deal to our understanding of the physics of earthquakes and the processes leading to earthquake nucleation and propagation. However, data is also needed along the other segments of the San Andreas that won't be drilled due to budget constraints. To take advantage and re-enter existing wells drilled and later abandoned close to the San Andreas, would enable us to more thoroughly conduct the type of insitu stress, heat-flow, chemical, and hydrologic experiments at reasonable depths. One such opportunity may be to re-enter two (2) abandoned exploration wells located 3 and $5 \mathrm{~km}$ west of the SAF (Carrizo Plains 1-16 and Tenneco 1-20 in Figure 3a). Each of these wells were drilled in the early 1980's to a depth of about $2.2 \mathrm{~km}$. The casing is at a depth of about $300 \mathrm{~m}$, leaving open hole conditions below to conduct the experiments just described. This field experiment would compliment the pilot hole at Parkfield proposed for the San Andreas Fault Zone Drilling Project.

Another aspect of this project has been to explore ways of advancing the current drilling and measurement technologies or create new technologies critical for the success of the San Andreas Fault Zone Drilling Project. One such project that was started as part of this LDRD project was 
the Advanced Tiltmeter Hydraulic Fracture Imaging and Modeling project. Although this new tiltmeter will be used for monitoring the geometry of the hydraulic fracture created during the deep hydraulic fracturing stress measurement stages of the drilling project, it has immediate applications in the oil and gas industry. Because nearly $50 \%$ of all production wells depend upon hydraulic fracturing treatments to enhance hydrocarbon production, knowing the orientation of the fracture has an important impact on designing and evaluating production field performance. Partial funding for this tiltmeter project came from the Natural Gas and Oil Technology Partnership in Fossil Energy within DOE.

Proposed stress, heat-flow, geochemical, and hydrologic experiments in the two abandoned holes situated near the SAF mentioned above could also include testing of instruments being designed at LLNL, such as the high resolution tiltmeter and slim hole seismometer. An avenue for funding such a project could be multi-institutional, including Basic Energy Sciences at DOE and IGPP. 


\section{References}

Anderson, E. M., 1951, The Dynamics of Faulting and Dike Formation with Applications in Britian, 2nd ed., Oliver and Boyd, Edinburge.

Angelier, J, 1979; Determination of the mean principal directions of stress for a given fault population, Tectonphysics, 56, T17-T26.

Bakun, W. H. and A. G. Lindh, 1985; The Parkfield, California, earthquake prediction experiment, Science, 229, 619-624.

Bakun, W. H. and T. V. McEvilly, 1984; Recurrence models and Parkfield, California, earthquakes, J. Geophys. Res., 89, 3051-3058.

Barton, C. A., M. D. Zoback, and K. L. Burns, 1988, In-situ stress orientation and magnitude at Fenton Hill geothermal site, New Mexico, Geophys. Res. Lett., 15, 467-470.

Barton, C. A., and M. D. Zoback, 1994; Stress perturbations associated with active faults penetrated by boreholes: Possible evidence for near-complete stress drop and a new technique for stress magnitude measurement, J. Geophys Res., 99, 9373-9390.

Blanpied, M. L., D. A. Lockner, and J. D. Byerlee, fault stability inferred from granite sliding experiments at hydrothermal conditions, Geophys. Res. Lett., 18, 609-612, 1991.

Brace, W. F. and D. L. Kohlstedt, 1980; Limits on lithospheric stress imposed by laboratory experiemtns, J. Geophys. Res., 85, 6248-6252.

Brune, J. N., T. L. Henyey, and R. F. Roy, 1969, Heat flow, stress, and rate of slip along the San Andreas fault, California, J. Geophys. Res., 74, 3821-3827.

Brune, J. N., 1993, Rupture mechanism and interface separation in foam rubber models of earthquakes: A possible solution to the heat-flow paradox and the paradox of large overthrusts, Tectonophy., 218, 59-67.

Byerlee, J. D., 1978; Friction of rock, Pure Appl. Geophys., 116, 615-626.

Byerlee, J. D., 1990, Friction, overpressure and fault normal compression, Geophys., Res. Lett., 17, 2109-2112.

Byerlee, J. D., A model for episodic flow of high pressure water in fault zones before earthquakes, Geology, 21, 303-306, 1993.

Castillo, D. A., and W. L. Ellsworth, 1993, Seismotectonics of the San Andreas Fault System Between Point Arena and Cape Mendocino in Northern California: Implications for the Development and Evolution of a Young Transform, J. Geophys. Res., 98, 6543-6560.

Castillo, D. A., 1993, State of stress near active plate boundaries: The San Andreas fault in northern and central California, and the Indo-Australian plate, south of Java, Ph.D. Dissertation, Stanford University, 289pp. 
Castillo, D. A. and Zoback, M. D., 1995, Systematic stress variations in the Southern San Joaquin Valley and along the White Wolf Fault: Implications for the rupture mechanics of the $1952 \mathrm{M}_{\mathrm{s}} 7.8$ Kern County earthquake and its contemporary seismicity, J. Geophys. Res., 100, 6249-6264.

Castillo, D. A. and Zoback, M. D., 1994, Systematic variations in stress state in the Southern San Joaquin Valley: Inferences based on wellbore data and contemporary seismicity, Bull. Am. Assoc. Petro. Geol., 78, 1257-1275.

Coulomb, C. A., 1773; Sur une application des regles de Maximis et Minimis a quelques problemes de statique relatifs a l'Architecture, Acad. Roy. des Sciences Memoires de math, et de physique par divers savans, 7, 343-382.

Davis, T. L., M. B Lagoe, W. J. M. Bazeley, S. A. Gordon, K. McIntosh, and J. S. Namson; 1988; Structure of the Cuyama valley, Calienta range, and Carrizo Plain and its significance to the structural style of the southern Coast Ranges and western trnsverse Ranges, in Tertiary tectonics and sedimentation in the Cuyama basin, San Luis Obispo, Santa Barabara, and ventura counties, edited by W. J. M. Bazeley, Field trip Guidebook, 59, pp. 141-158, Pac. sect. S.E.P.M.

Eberhart-Phillips, D., M. Lisowski, and M. D. Zoback, 1990; Crustal strain near the big bend of the San Andreas Fault; Analysis of the Los Padres-Tehachapi trilaterations networks, California, J. Geophys. Res., 95, 1139-1153.

Ellsworth, W. L., Historical Seismicity, in The San Andreas Fault System, R. E. Wallace, ed., $U$. S. Geol. Surv. Professional Paper 1515, 115-152, 1990.

Grant, L. B., and A. Donnellan, 1994; 1855 and 1991 surveys of the San Andreas fault: Implications for fault mechanics, Seis Soc. Am. Bull., 84, 241-246.

Grant, L. B., and K. E. Sieh, 1994; Paleoscismic evidence of clustered earthquakes on the San Andreas fault in the Carrizo Plain, California, J. Geophys. Res., 99, 6819-6841.

Henyey, T. L., and G. L. Wasserburg, 1971, Heat flow near major strike-slip faults in California, J. Geophys. Res., 76 , 7924-7946.

Hickman, S., and M. D. Zoback, 1996; In-situ stress in a fault-hosted geothermal reservoir at Dixie Valley, Nevada, in Faulting, Fault Sealing and Fluid Flow in Hydrocarbon Reservoirs Conference, University of Leeds, 23-25 September, 1996, 100-101.

Hickman, S. H., M. D. Zoback, and J. H. Healy, 1988; Continuation of a deep borehole stress mesurements profile near thge San Andreas fault: 1. Hydraulic fracturing stress measuremetns at Hi Vista, Mojave Desert, California, J. Geophys. Res., 93, 15,18315,195 . 
Hickman, S., M. D. Zoback, W. L. Ellsworth, and L. W. Younker, 1994; Deep scientific drilling in the San Andreas fault zone, Abstracts of the Workshop on Investigations of Lithosphere Architecture and Development, Taos, NM., November 5-9, 1994.

Hickman, S., L. W. Younker, M. D. Zoback, and G. Cooper, 1995; The San Andreas Fault Zone Drilling Project: Scientific objectives and technological challenges, J. Energy Resources Technology, 117, 263-270.

Hubbert, M. K., and D. G. Willis, 1957; Mechanics of hydraulic fracturing, J. Pet. Technol., 9, 153-168.

Jaeger, J. C., and N. G. W. Cook, 1979; Fundementals of Rock Mechanics, 3rd ed., 593 pp., Chapman and Hall London.

Jones, L. M., Focal mechanisms and the state of stress on the San Andreas fault in Southern California, J. Geophys. Res., 93, 8869-8891, 1988.

Lachenbruch A. H., 1980, Frictional heating, fluid pressure, and the resistance to fault motion,J. Geophys. Res., 85, 6097-6112.

Lachenbruch A. H. and J. H. Sass, 1973, Thermal-mechanical aspect of the San Andreas fault system, in Proceedings of the Conference on the Tectonic Problems of the San Andreas fault System, R. L. Kovach and A. Nur, eds.,Stanford University Press, 192-205.

Lachenbruch A. H. and J. H. Sass, 1980, Heat flow and energetics of the San Andreas fault zone, J. Geophys. Res., 85 , 6185-6222.

Lachenbruch A. H. and A. McGarr, 1990, Stress and heat flow, in The San Andreas Fault System, California, R. E. Wallace (ed.) pp. 261-277, U. S. Geol. Surv. Prof. Paper 1515.

Lachenbruch A. H. and J. H. Sass, 1992, Heat flow from Cajon Pass, fault strength and tectonic implications, J. Geophys. Res., 97 , 4995-5015.

Lawson, A. C. and others, 1908; The California eathquake of April 18, 1906, Carnegie Institution of Washington, Report of the earthquake investigation committee 1908.

Lyzenga, G. A., A. Raefsky, and S. G. Mulligan, 1991; Models of recurrent strike-slip cycles and the state of crustal stress, J. Geophys. Res., 96 , 21,623-21,640.

Lisowski, M, J. C. Savage, and W. R. Prescott, 1991; The velocity field along the San Andreas fault in central and southern California, J. Geophys. Res., 96 , 8369-8389.

McGarr, A., 1980; Some constraints on levels of shear stress in the crust from obsevations and theory, J. Geophys Res., 85, 6231-6238.

Melosh, H. J., 1979; Acoustic fluidization: A new geologic process?, J. Geophys. Res., 84 , 7513-7520.

Melosh, H. J., 1996; Dynamic weakening of faults by acoustic fluidization, Nature, 379 , 601-606. 
Moore, D. E., D. Lockner, and R. Summers, 1996; Strength of chrysotile-serpentinite gouge under hydrothermal conditions: Can it explain a weak San Andreas fault? Geology, Submitted.

Mount, V. S. and J. Suppe, 1987, State of stress near the San Andreas fault: Implications for wrench tectonics, Geology, 15, 1143-1146.

Mount, V. S. and J. Suppe, 1992, Present-day stress orientations adjacent to active strike-slip faults: California and Sumatra, J. Geophys. Res., 97, 11,995-12,013.

Oppenheimer, D. H., P. A. Reasenberg, and R. W. Simpson, 1988; Fault-plane solutions for the 1984 Morgon Hill, California earthquake sequence: Evidence for the state of stress on the Calaveras fault, J. Geophys Res., 93, 9007-9026.

Reches, Z., G. Schubert, and C. Anderson, 1994; Modeling of periodic great earthquakes on the San Andreas fault: Effects of nonlinear crustal rheology, J. Geophys Res., 99, 21,98322,000.

Rice, J. R., 1992, Fault stress states, pore pressure distributions, and the weakness of the San Andreas fault, in Earthquake Mechanics, Rock Deformation and Transport Properties of Rocks, edited by B. Evens and T. F. Wong, Academic Press, London, 475-503.

Scholz, C. H., 1989; Mechanics of faulting, Ann. Rev. Earth Planet. Sci, 17, 309-334.

Scott, D. R., 1996; Seismicity and stress rotation in granular model of the brittle crust, Nature, 381, 592-595.

Sibson, R. H., 1973; Interactions between temperature and pore-fluid pressure during earthquake faulting: A mechanism for partial and total stress relief, Nature Phys. Soc., 243, 66-68.

Sibson, R. H., 1983; Continental fault structure and the shallow earthquake source, J. Geol. Soc. London, 140, 741-767.

Sieh, K. E., and R. H. Jahns, 1984; Holocene activity of the San Andreas Fault at Wallace Creek, California, Geol. Soc. Amer. Bull., 95, 883-896.

Sims, J. D., 1993; Chronology of displacement on the San Andreas fault in Central california: Evidence from reversed positions of exotic rock bodies near Parkfield, California, in The San Andreas fault system; displacement, palinspastic reconstruction, and geologic evolution, edited by R. E. Powell, R. J. Weldon II and J. C. Matti, Memoir, 178, pp. 231256, Geol. Soc. Amer.

Stock J. H., and J. H. Healy, 1988; Continuation of a deep borehole stress mesurements profile near thge San Andreas fault: 2. Hydraulic fracturing stress measuremetns at Black Butte, Mojave Desert, California, J. Geophys. Res., 93, 15,196-15,210. 
Stock, J. M., J. H. Healy, S. H. Hickman, and M. D. Zoback, 1985, Hydraulic fracturing stress measurements at Yucca Mountain Nevada, and relationships to the regional sstress field, J. Geophys Res., 90, 8691-8706.

Vernik, L., and M. D. Zoback, 1992; Estimations of the maximum horizontal principal stress magnitude from stress-induced wellbore breakouts in the Cajon Pass scientific research borehole, J. Geophys Res., 97, 5109-5119.

Wallace, R. E., 1968; Noteson stream channels offset by the San Andreas fault, souther Coast Ranges, California, in Proceedings of the conference on geologic problems of the San Andreas Fault, edited by W. R. Dickinson and A. Grant, 11 pp, Stanford University Publications in the Geologic Sciences.

Wallace, R. E., 1990; General Features and Geomorphic Expression, in The San Andreas Fault System, R. E. Wallace, ed., U. S. Geol. Surv. Professional Paper 1515, 3-21.

Zoback, M. D., and S. Hickman, 1982; In situ study of the physical mechanisms controlling induced seismicity in Montcello reservoir, South Carolina, J. Geophys Res., 87, 69596974.

Zoback, M. D., and J. H. Healy, 1984; Friction, faulting and in-situ stress, Annales Geophysicae, 2, 689-698.

Zoback, M. D., M. L. Zoback, V. S. Mount, J. Suppe, J. P. Eaton, J. H. Healy, D. Oppenheimer, P. Reasenberg, L. Jones, C. B. Raleigh, I. G. Wong, O. Scotti, and C. Wentworth, 1987, New evidence on the state of stress of the San Andreas fault system, Science, 238, 1105-1111.

Zoback, M. D., and G. C. Beroza, 1993, Evidence for near-frictionless faulting in the 1989 (M 6.9) Loma Prieta, California, earthquake and its aftershocks, Geology, 21, 181-185.

Zoback, M. L. and Zoback, M. D., Tectonic stress field of the conterminous United States: Geol. Soc. Am. Mem., 172, 523-539, 1991.

Zoback, M. D., S. Hickman, L. W. Younker, and W. L. Ellsworth, 1995; Strong plates and weak plate boundaries: Reconciling relative plate motions, plate-driving forces and intraplate seismicity through scientific drilling, Abstracts XXI General Assembly of the International Union of Geodesy and Geophysics, Boulder, CO. 


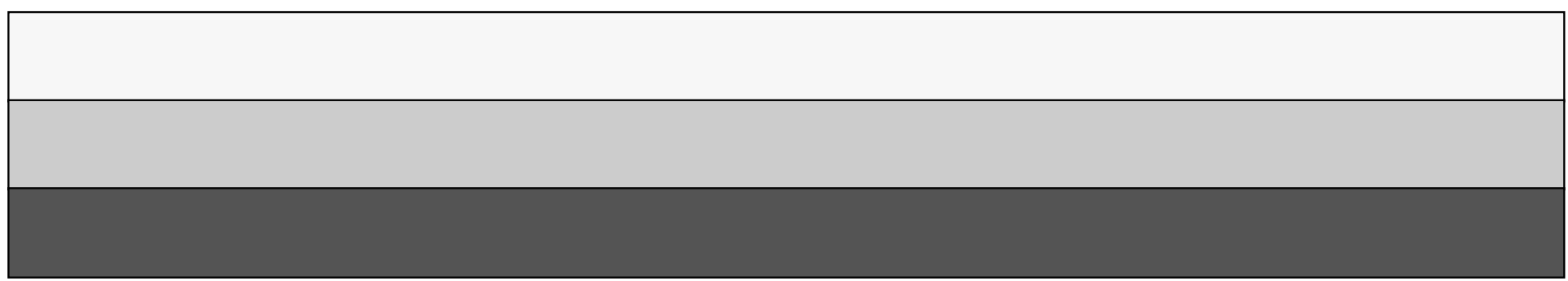

